NBER WORKING PAPER SERIES

\title{
WHEN INFORMATION IS NOT ENOUGH: EVIDENCE FROM A CENTRALIZED SCHOOL CHOICE SYSTEM
}

\author{
Kehinde F. Ajayi \\ Willa H. Friedman \\ Adrienne M. Lucas \\ Working Paper 27887 \\ http://www.nber.org/papers/w27887 \\ NATIONAL BUREAU OF ECONOMIC RESEARCH \\ 1050 Massachusetts Avenue \\ Cambridge, MA 02138 \\ October 2020
}

For useful comments and suggestions we thank Felipe Barerra-Osorio, Jim Berry, Eric Chyn, Justine Hastings, Chris Neilson, Jeremy Tobacman, and seminar participants at Georgetown University, Harvard Graduate School of Education, Howard University, the University of Delaware, the University of Minnesota, the E-con of Education Virtual Seminar, and the Ghana Education Evidence Summit. We gratefully acknowledge funding from the Post-Primary Education Initiative of the Jameel Poverty Action Lab (J-PAL), the Weiss Family Program Fund, and the University of Delaware Institute for Global Studies' Global Exchange Program. For exceptional support in Ghana we thank Kym Cole, Jonathan Addie, Cornelius Adjei, and Helen Habib. Phillip Ross provided excellent research assistance. The findings, interpretations, and conclusions expressed in this paper are entirely those of the authors and do not necessarily represent the views of the World Bank, its Executive Directors, the National Bureau of Economic Research or the governments of the countries they represent. AEA RCT Registry number AEARCTR-0001017. The Boston University, Innovations for Poverty Action, and University of Delaware IRBs approved this project. Ghana Education Service reviewed and approved the research protocol.

NBER working papers are circulated for discussion and comment purposes. They have not been peer-reviewed or been subject to the review by the NBER Board of Directors that accompanies official NBER publications.

(C) 2020 by Kehinde F. Ajayi, Willa H. Friedman, and Adrienne M. Lucas. All rights reserved. Short sections of text, not to exceed two paragraphs, may be quoted without explicit permission provided that full credit, including $\odot$ notice, is given to the source. 
When Information is Not Enough: Evidence from a Centralized School Choice System Kehinde F. Ajayi, Willa H. Friedman, and Adrienne M. Lucas

NBER Working Paper No. 27887

October 2020

JEL No. D84,I21,I24,I25,O15

\section{$\underline{\text { ABSTRACT }}$}

Students often make school choice decisions with inadequate information. We present results from delivering information to randomly selected students (and some randomly selected parents) across 900 junior high schools in Ghana, a country with universal secondary school choice. We provided guidance on application strategies and reported the selectivity and exit exam performance of secondary schools, information students and parents prioritized. We find that despite information changing the characteristics of schools to which students applied and students gaining admission to higher value-added schools, they were not more likely to matriculate on time or at all. Information was not the only constraint.

Kehinde F. Ajayi

The World Bank

1818 H St NW

Washington, DC 20433

kajayi@worldbank.org

Willa H. Friedman

Department of Economics

University of Houston

3623 Cullen Boulevard Room 204

Houston, TX 77204-5019

willa.friedman@gmail.com
Adrienne M. Lucas

Lerner College of Business and Economics

University of Delaware

419 Purnell Hall

Newark, DE 19716

and NBER

alucas@udel.edu

A randomized controlled trials registry entry is available at https://www.socialscienceregistry.org/trials/1017 


\section{Introduction}

Each year, millions of families face the daunting task of selecting a school for their child to attend. School choice can offer families an array of academic options, but families can only accurately apply their preferences when they have adequate information about the available alternatives. Previous research from settings as varied as Boston, China, Ghana,

Kenya, and Mexico has shown that families (especially those from lower socio-economic backgrounds) lack critical information, leading to sub-optimal choices and an inefficient allocation of household and schooling sector resources (Abdulkadiroğlu et al., 2006; Pathak and Sönmez, 2008; Lai et al., 2009; Lucas and Mbiti, 2012; Ortega Hesles, 2015; Ajayi et al., 2017).

This paper investigates the effects of information on school choice. We focus on three questions: 1) What information do parents and students say they want? 2) Does receiving this information affect their school choices and educational outcomes? 3) Does who receives this information matter? To address these questions, we conducted a randomized controlled trial in 900 junior high schools in Ghana, a country with universal secondary school choice. We designed and distributed a booklet, produced and screened a video, and facilitated a school-based workshop to close the information gaps that students, parents, and researchers had identified as barriers to efficient secondary school choice and evidence of information deficiencies-37 percent of students matriculate to a school other than the one to which they were admitted and fewer than half of students who matriculate in the first year after junior high school do so in the first six weeks of the academic year. Together, the intervention provided information on both how to navigate the school choice process and the characteristics of available secondary schools. We then experimentally varied receipt of this information among students in their final year of junior high school and their parents.

Theoretically, providing agents with information, especially the information they say they want, should result in more informed decisions and better outcomes. We find that even though our information was what principals, teachers, parents, and students stated would 
help them make more informed choices and was salient, our information campaign did not change the likelihood of enrollment or on-time matriculation. We confirm that respondents received, believed, and understood the information provided. Respondents even remembered specific details of the intervention materials more than one year later. The information changed students' application decisions, but it did not improve students' outcomes during the transition to secondary school. We generally do not find any differential impacts of targeting students versus parents directly, with the exception of changing students' reported application priorities.

Despite the importance of school choice in many education systems, relatively few studies have looked at ways to improve students' interactions with existing centralized systems. Information interventions have focused on improving student applications to schools in noncentralized systems (e.g., Hoxby and Turner (2013) in US higher education; Allende et al. (2019) for Chilean primary schools), student sorting to higher quality schools or pressuring schools to improve in systems without formal applications (Banerjee et al., 2010; Mizala and Urquiola, 2013; Andrabi et al., 2017), how to finance higher education (Dinkelman and Martinez, 2014; Dynarski et al., 2018), the importance of peer networks (Dustan, 2018), the returns to schooling (Jensen, 2010), and updating beliefs about one's own ability (Bobba and Frisancho, 2019; Barrera-Osorio and Deming, 2020). Another avenue of research has advocated for changes to existing systems (Abdulkadiroğlu et al., 2006; Grenet et al., 2019; Kapor et al., 2020).

Information could be especially valuable in centralized systems where students have limited ability to sort ex post or to gain admission to multiple schools ex ante. More than 30 countries use centralized school choice systems for primary or secondary school and 46 countries use it for tertiary education (Neilson, 2019). Three existing studies focused directly on the effect of information provision on students' choices in such systems. Two of the interventions focused on simplifying and amplifying information already available. Relative to a control group that had access to a 100 page book on schools, Hastings and Weinstein 
(2008) found that providing simplified information to parents on the test score performance of schools in Charlotte-Mecklenburg Public School District in North Carolina led to parents choosing schools with higher test scores. Corcoran et al. (2018) provided students selecting high schools in New York City with a one-page list of 30 geographically proximate schools with higher than median graduation rates. This intervention caused students to be more likely to match with higher-performing schools. ${ }^{1}$ In a much less information rich environment, Ajayi et al. (2017) found that directly targeting parents in Ashanti Region, Ghana caused them to be more engaged in the school choice process using evidence from the same experiment as the current study.

Further, few studies have experimentally varied who receives the information. In the above settings, information typically targeted the entire household or community through mailings, newspapers, village meetings, or through banners advertising success at schools. ${ }^{2}$ In Ghana, especially with low levels of parental literacy, students are often the primary conduit of information for their parents. Informing only students and teachers is easier and less expensive as they are accessible at school. Informing parents is more costly for parents and information providers because parents must be mobilized to receive information. However, targeting parents can magnify the effect of information provision. Parents generally pay for education expenses and often intervene in school choice ex post even if they are not aware of students' choices ex ante.

Our findings have implications for the implementation and design of these school choice systems, particularly with regard to ensuring equal opportunities for students from underprivileged backgrounds. Additionally, we provide evidence that improving information, even by offering the information respondents want, may not be sufficient to overcome other structural barriers to improved decision making.

\footnotetext{
${ }^{1}$ Other arms of the intervention layered additional treatments in addition to this list, but in most cases the authors are unable to reject equality with the basic treatment.

${ }^{2}$ Most studies that have tried to estimate the role of parents in students' decision-making did not engage parents directly, instead varying whether students were asked to pass along information to parents (Dinkelman and Martinez, 2014) or varying the addressee on a mailing (Hoxby and Turner, 2013).
} 


\section{Schooling and School Choice in Ghana}

\subsection{Schooling System}

Ghana's school year consists of three terms, with the academic year starting in September and ending in July. The 6-3-3 system consists of 6 years of primary school (P1 through P6), three years of junior high school (JHS1 through JHS3), and three years of secondary, i.e. senior high, school (SHS1 through SHS3). Ghana has two types of secondary schools: an academic track and a technical/vocational track. Students in both tracks attend a specific program within their schools, e.g. General Science in academic track or welding in technical/vocational track. ${ }^{3}$ Almost all academic track schools offer boarding options, enabling students from anywhere in the country to attend.

Students take two nationally standardized exams during their pre-tertiary years of schooling. At the end of JHS3, students take the Basic Education Certificate Examination (BECE). At the end of SHS3, students take the West African Senior School Certificate Examination (WASSCE). Passing these exams is a requirement to earn the equivalent of a diploma, and scores on the exams determine whether and what kind of additional schooling students can pursue.

During the period under study, both primary and junior high school were tuition-free, but senior high schools still required fees. For the 2016-2017 school year, the period of study, approved academic year fees at a government secondary school were GHC551.50 (USD\$143) for day students and GHC1494.50 (USD\$387) for boarding students. ${ }^{4}$ Many government schools unofficially charged additional fees such as parent teacher association dues, teacher motivation fees, infrastructure improvement levies, and exam registration fees. ${ }^{5}$ Private

\footnotetext{
${ }^{3}$ The seven academic programs are Agriculture, Business, General Arts, General Science, Home Economics, Technical, and Visual Arts, and not all schools have all programs.

${ }^{4}$ Charges varied by term. First term allowable charges were GHC405.50 (USD $\$ 105$ ) for day students and GHC724.50 (USD \$187) for boarding students. For terms two and three, the per-term allowable charges were GHC73 (USD \$19) for day students and GHC385 (USD\$100) for boarding students. Exchange rate based on the September 1, 2016 exchange rate of 1 USD equal to 3.8665 GHC. Expressed in 2016 dollars.

${ }^{5}$ Including all school-specific and approved feeds, Duflo et al. (2017) reported per year average annual costs of secondary school of GHC 1921 for the cohort that graduated in 2012, about 30 percent higher than
} 
schools were free to set their own fee schedule.

\subsection{School Choice System}

Students are admitted to at most one secondary school-program pair through a centralized admissions process implemented by the Ghana Education Service Computerised School Selection and Placement System (CSSPS). During the second term of JHS3, students register for the Basic Education Certificate Examination (BECE) and submit the four secondary school-program pairs to which they are applying to the CSSPS. Each student must list four choices.

Rules constrain students' choices. Students can only apply to one program at each school. Each secondary school has an "Option" designation. Options 1 through 3 are public, academic track, secondary schools, with option numbers approximately inversely ranked by historic difficulty of admission. ${ }^{6}$ Students can list at most one Option 3 school (the most competitive), two Option 2 schools, and four Option 1 schools. Public technical/vocational schools are Option 4. All private schools (including both academic track and technical/vocational schools) are Option $5 .{ }^{7}$ Options 4 and 5 are typically not competitive to enter and very few students list these schools as they can gain entry outside of the centralized allocation system by applying directly to the schools for admission since these schools are often undersubscribed. ${ }^{8}$

A "catchment area option" adds additional complexity. Students who only select schools within $16 \mathrm{~km}$ of their JHS can select this option, which can increase their odds of admissions,

the 2016 boarding allowable charges.

${ }^{6}$ The options do not perfectly correspond to recent admissions cut-offs.

${ }^{7}$ A separate, elite private school sector that provides an international curriculum and caters primarily to wealthy households and foreign nationals operates outside the CSSPS system. Students in that system typically come from international curriculum junior high schools and do not take the BECE or the WASSCE.

${ }^{8}$ In our data only about 1 percent of students listed a private school as one of their choices. Of those who do, they are most likely to list it as choice 4. Private schools are generally considered less desirable than government schools as they are more expensive and have equivalent or worse exit exam scores. In the CSSPS assignment, almost all students admitted to a private school are those with BECE scores below 250, a level considered marginally passing. About 8 percent of students listed a technical/vocational school as one of their four choices. 
as each academic track school must set aside 30 percent of their seats in each program for students who select this option. In our sample, 14 percent of students chose only secondary schools within $16 \mathrm{~km}$ of their JHS, and this fraction does not vary by treatment group.

After students have completed the BECE in June, the CSSPS admits each student to at most one school. First, schools submit the number of seats available for first year students in each program. Then, the CSSPS uses a deferred acceptance algorithm to generate a list of students admitted to each school-program based on the number of seats available in each school-program, students' test scores, and students' preferences. ${ }^{9}$ After all preferences have been considered, students with the highest test scores who were not matched to one of their preferred schools are arbitrarily allocated to schools with remaining seats. Students and schools are told of the matches in September, shortly before the start of the academic year.

Once the school year starts, schools assess how many admitted students failed to matriculate and can fill these seats at their discretion with students who directly applied to the school. ${ }^{10}$ This unofficial second round lasts throughout the first term of secondary school, resulting in students starting school late as they and their parents visit different schools trying to find an available match and this idiosyncratic process gives families no guarantee of admission.

A system of centralized school choice is not unique to Ghana. China, Kenya, Lesotho, Liberia, Mexico, Romania, Trinidad and Tobago, Uganda, and Zambia use similar systems combining students' stated preferences with test scores to determine secondary school assignments. More than 30 countries use a centralized school choice process for primary or secondary school (Neilson, 2019). Further, an analogous system operates in some US

\footnotetext{
${ }^{9}$ The CSSPS considers the first choices of all applicants. It conditionally admits the highest scoring applicants up to each school-program's capacity in the first round. For students not admitted to their first choice, it then considers their second choice. It compares students' scores relative to the scores of the conditionally admitted applicants from the first round, and replaces any conditionally admitted applicants from the previous round with students with higher test scores (i.e., through a deferred acceptance algorithm). These displaced students' second choices are then considered. This process repeats for choices 3 and 4 . This algorithm yields an allocation equivalent to a serial dictatorship where students are ranked by descending score and the preferences of higher scoring students have precedence. As students are limited in their choices, this allocation mechanism is not strategy proof, but students should list their choices in order of preference.

${ }^{10}$ Schools are supposed to report unfilled seats to the CSSPS secretariat for a centralized supplementary allocation of students, but this does not happen in practice.
} 
school districts for admissions to elementary, middle, and secondary schools with assignment through preferences and a lottery. Even though in the US students are often ranked by a lottery instead of a test score, issues of students and households having incomplete information about schooling choices are similar.

The centralized admissions process has some beneficial features for students. First, students can apply to any secondary school in the country. Second, by design, admissions to secondary school are based on expressed preferences and test scores, not subject to manipulation based on wealth or family connections.

Unfortunately, the process can be quite daunting for students. Previous research has shown that many students - especially the most marginalized - make their choices with limited information about options, resulting in choice errors (Lucas and Mbiti, 2012).

\section{Inefficiencies and Conceptual Framework}

In this section we first describe the inefficiencies that are generated in the low-information setting, then we outline a conceptual framework for how our improved information should remedy some of these issues.

\subsection{Inefficiencies}

In Ghana, students submit their preferences often with limited knowledge about schools, their admission likelihoods, or how to get the most out of their applications. This information deficit can be more acute among the most marginalized (Lucas and Mbiti, 2012). Conditional on their own scores, students from lower performing junior high schools apply to and are admitted to less selective secondary schools than equally qualified students from higher performing junior high schools (Ajayi, 2013). In addition to potentially worse matches for students, this lack of information creates wasted resources on a number of margins for both households and the schooling sector. 
Once students receive their admission decisions, they can deviate from their officially admitted school if another school will admit them. The process through which these deviations happens is very expensive to households in both time and money and in most cases the new school is one to which the student could have been admitted had it been listed originally.

To deviate from the official admission decision, parents have to travel to the school to appeal directly, in person, to the school principal. School principals maintain waiting lists of students to admit once other officially admitted students do not matriculate. Well into the second month of school, schools do not know which students will matriculate. Some students (4 percent) are forced into this option because they did not correctly complete their choice forms and are not admitted to any school. Others opt into this method of ex post matching. Of students who were admitted to a senior high school, 37 percent matriculated to a school other than their CSSPS matched school. Based on conversations with students and parents, they would prefer to forgo this ex post matching as it is both costly and risky — students might not be admitted to another school. This ex post matching results in delayed matriculationonly 45 percent of students who were attending secondary school by the second term of the first year started in the first six weeks of school. Students then start school already behind and households must pay the fees associated that first month regardless of when students start. In conversations with secondary school officials, they lamented that students who arrive late are often both behind their peers who started on time and arrive with an attitude not conducive to learning because they delayed school entry to try to matriculate to another school.

Once students matriculate, about 7 percent attend schools where fewer than 25 percent of students who attempt the WASSCE, the secondary school exit exam, pass. Passing the WASSCE certifies senior high school completion and is used in employment as proof of school completion. Students continue to select these low pass rate schools despite the availability of schools with similar admissions criteria and higher pass rates. Failing the WASSCE means the household wasted three years of school fees and the student incurred three years of 
opportunity costs without earning the equivalent of a secondary school diploma.

At the sector level, the churn in students that happens in the first term leads to teachers teaching to partially empty classrooms and wastes school administrator time that could be better spent on the educational mission of the school. As the government partially subsidizes school fees and pays teacher salaries, these are additional costs borne by the government. Finally, the government also incurs costs in providing the years of schooling for those students who attend schools in which very few students pass the WASSCE.

In most school choice settings, admissions are a zero-sum game (i.e. when one student is admitted, then another is not). In this setting, given the extensive ex post matching process, students being admitted by the CSSPS to their eventual school would be pareto improving.

Further, what one student perceives as a good match might not be a good match for another student. Therefore, a student could have an improved match by learning more about a school in advance without necessarily making another student worse off. Regardless of quantitative assessments of school quality, students who are more pleased with their matches put forth more effort (Hastings et al., 2012) and students who are better matches with their college majors have higher labor market returns, even if the average return to the major is low (Kirkeboen et al., 2016). Given the delays in matriculation and failure to matriculate at all, substantial scope exists to improve the match between students and schools without necessarily making some students worse off.

\subsection{Conceptual Framework}

A student's matriculation decision reflects match quality through revealed preference. Our intervention sought to increase the match quality between students and schools, resulting in more students starting secondary school on time in the school to which they were originally admitted, reducing both household and sector inefficiencies and resulting in better longer run student outcomes.

From students considering their choices at the end of JHS3, a number of steps are nec- 
essary along the causal chain to ultimately affect their matriculation decision at the start of SHS1. In this sub-section we outline the steps of the causal chain and in the next section we explain how our intervention sought to improve each of these steps.

All students in our study, both control and treatment, were enrolled in JHS3, the final year of junior high school, at the start of the study.

Step 1: Students receive information about school choices and how to correctly and strategically apply to senior high schools. During their final year of junior high school, and maybe even before, students receive information of varying quality from peers, siblings, parents, teachers, and other sources. Our intervention increased both the quality and quantity of this information.

Step 2: Students use and internalize the information, potentially changing their preferences over school characteristics and enabling them to make more informed decisions about the school-program pairs they might select.

Step 3: Students register for the BECE and list their four school-program choices.

Step 4: Students take the BECE. While not designed to impact BECE scores, information about schools could have encouraged students to put forth more effort on the BECE.

Step 5: The CSSPS combines students' BECE scores, stated preferences, and available spaces in each school-program pair to admit each student to at most one school-program pair.

Step 6: Students matriculate to the school-program to which they were admitted, engage in time intensive ex post sorting and matriculate to another school, or do not matriculate at all.

Our intervention occurred in Step 1-receiving information. We collected both administrative and survey data as appropriate for each of the subsequent steps. Figure 1 displays this theory of change.

[Figure 1 about here] 


\section{The Intervention}

Given the inefficiencies that inadequate information introduces into the secondary school selection process, we sought to remedy the information deficit to increase the likelihood that students matriculate on time and continue their education. To ensure that our intervention was contextually relevant, we asked students their most important characteristics for school selection. Figure 2 displays their responses. The most important characteristic was academic performance followed by distance and cost. Other important characteristics were admission chances, future success, teacher quality, and whether the school was single gender.

[Figure 2 about here]

The schooling decision often involves the whole household and could also involve school personnel. We asked students who the most helpful person was in making their school choices. Overwhelmingly, students responded their parent or guardian, followed by sibling, head teacher (i.e. school principal), and classroom teacher (Figure 3). The importance of parents was reinforced through focus group discussions with parents and students who stated that one of the reasons students did not attend the school to which they were admitted was because parents did not like it and were not aware that the student had applied until after they were admitted.

[Figure 3 about here]

Based on the important characteristics and decision makers, we created a three-part information campaign: a booklet, a video, and a workshop. We called the package GuIIDEGuidance and Information for Improved Decisions in Education.

GuIIDE Booklet. First, we created a booklet with information on the CSSPS process and details about each secondary school. The booklet was in English, the official language of instruction in JHS in Ghana. The booklet had two parts: information on application rules 
and strategies, and information about secondary schools in the Ashanti Region. ${ }^{11}$

In the first part of the booklet, we provided students with the CSSPS rules about how many choices of each Option they were allowed to list, two simple strategies (do not list more competitive schools after less competitive schools and include a variety of schools in case the student's BECE score is higher or lower than expected), details about the catchment area option, and government approved secondary school fees for both day and boarding students. The section also contained a worksheet for students to calculate their likely raw percentage BECE score. This score is used for admissions, but we learned through piloting that students typically do not think about raw BECE scores. Therefore, the first challenge for students when confronted with historical admission scores is to alter their thinking about their expected score from a 9 (worst) to 1 (best) scale to a 0 (worst) to 100 (best) scale. ${ }^{12}$ Figure 4 is the first content page of the booklet, outlining the application process and recommended strategies for selecting schools.

[Figure 4 about here]

The second part, and bulk of the booklet, was devoted to statistics about each secondary school in the Ashanti Region. ${ }^{13}$ For each secondary school, we included both information that was potentially available elsewhere, but in a more useful format, and information that was not available elsewhere. We included the official school code that students submit on the CSSPS form; the school name and nickname if relevant (e.g. Opoku Ware Senior High

\footnotetext{
${ }^{11}$ We limited our intervention to JHS in Ashanti Region and only provided information on secondary schools in Ashanti Region for two reasons. First, Ashanti was the largest of Ghana's 10 regions by population and home to 20 percent of Ghana's population (subsequent to this study, the 10 regions were subdivided into 16 regions, Ashanti was not subdivided and remains the largest by population). Second, historically over 85 percent of students from Ashanti who attended secondary school did so in Ashanti. Students from other regions were more likely to attend secondary school outside their local region.

${ }^{12}$ The BECE consists of nine subject exams but a student's score is determined by the scores on the four core subjects and two next best subjects. Most students think and talk about their aggregate BECE score that appears on their BECE certificate - each subject graded on a scale from 9 to 1 with 1 being best. Therefore, an aggregate score on the BECE of 6, i.e. six scores of 1, is the highest score possible. Admission to secondary schools is instead based on the raw score in which each of the six subject scores is measured from 0 to 100 with 100 being the best. This is equivalent to the percentage correct on each subject exam.

${ }^{13}$ In 2016, Ashanti had 8 Option 3 schools (most competitive), 27 Option 2 schools, and 67 Option 1 schools.
} 
School is more commonly known as OWASS); the school's district and town or neighborhood; whether the school is single gender or mixed; whether the school is boarding, day, or mixed; and the programs offered. Ghana Education Service (GES), an agency of the Ministry of Education, produced a register of schools with most of this information, except the nickname. One copy of this register was left at the District Education Office for each JHS. Based on conversations with school leaders, many schools did not retrieve this register while others did, but did not share the information with their students.

We also provided information that was not available elsewhere. Based on administrative data from the CSSPS over the last three years, we included two measures designed to capture the competitiveness of admission to a particular school-program pair. First, we included the average BECE score of students admitted to the pair. Second, we included the BECE score of the 5th percentile admitted student-effectively the score threshold for admission. ${ }^{14}$ Finally, we included a measure of school quality. At the school level, we provided the number of students who took the WASSCE (the exam at the end of secondary school) and the overall pass rate. Due to our data sharing agreement, we were unable to include any measures of value added in the booklet. During the intervention school workshops (see more below), facilitators encouraged students and parents to consider WASSCE pass rates relative to average incoming BECE scores, effectively value added. The pass rate by program was not available. Figure 5 explains the layout of the school information.

\section{[Figure 5 about here]}

The booklet presented data by Option and by district. The full data, including programs and incoming BECE test scores, were organized alphabetically by school within each Option. School level data (code, name, district, gender, boarding, WASSCE performance, and Option) without the programme information were presented in the back, organized by district,

\footnotetext{
${ }^{14}$ Prior to our developing the GuIIDE booklet, no centralized source of information on admission scores existed. The CSSPS displayed a printed list of admitted students at each secondary school, along with admits' raw scores, but did not publish this information centrally. Prior to our booklet, students would need to collect information directly from each secondary school to know all the admission criteria.
} 
enabling students to quickly compare schools in the same district or to find a school's Option (and additional data) knowing only the school's district and name.

GuIIDE Video. The second component of the intervention was a video. Following the example of previous studies using videos to present information (e.g., Dupas, 2011; Dinkelman and Martinez, 2014; Banerjee et al., 2015) we wrote and produced a video on the school choice process to make the booklet more salient and memorable to students. ${ }^{15}$ In our video, a drama club from an Accra junior high school acted out a dramatized version of students using, understanding, and benefiting from the booklet, leading them to make more informed school choices. ${ }^{16}$ The video also modeled how to have a conversation with parents about choices and priorities.

We provided both an English and a Twi (the most common mother tongue in Ashanti) dubbed version of the video. Facilitators asked each head teacher to select which video should be screened in their school.

GuIIDE Workshop. The third component was a workshop. Facilitators distributed and explained the booklet and screened the video during at-school workshops in January, near the start of the second term of the school year. During these workshops, the facilitator also answered students' questions and did any necessary spot translation into Twi.

Because of the importance of parents in the decision making process, in some schools an additional workshop was held for parents only, at a time and day that the school expected parents to be available. Parents similarly watched the video and interacted with a facilitator. They did not receive an additional booklet.

By providing students, and sometimes parents, additional information and resources on

\footnotetext{
${ }^{15}$ The CSSPS has a video available online that explains the history and purpose of the CSSPS process but does not provide guidance on how to navigate it.

${ }^{16}$ The plot focused on two students-Serwah and Krampah-and their school choice process, successes, and missteps. Serwah was a diligent student who was not the top in her class but worked very hard and paid attention to the importance of the CSSPS. Krampah had higher test scores on mock BECE exams but did not take the CSSPS process seriously. After the BECE, Serwah was very happy being admitted to her second choice school while Krampah was not sure what he would do for secondary school since he did not have a high enough BECE score to get into his first choice school and had not paid attention to his other choices.
} 
the school choice process, we hoped to assist students in making choices that would better match their preferences, increasing match quality and reducing ex post sorting.

\section{$5 \quad$ Methodology}

\subsection{Research Design}

To test the impact of information on school choice, we conducted a 900-school randomized controlled trial (RCT). We randomly assigned 900 junior high schools in Ashanti, Ghana to one of three groups: T1) information to students and teachers, T2) information to students, teachers, and parents, and T3) control. Students and teachers in T1 and T2 schools received the full GuIIDE intervention-the booklet, video, and workshop during school hours. In addition, in T2 schools, we held parent workshops, providing information directly to parents. Students and parents in T3 schools continued with the status quo, receiving no additional information.

We overlaid this primary randomization with a secondary experiment on priming. Half of each group participated in a baseline survey in January of 2016, prior to any workshops, and half did not. This baseline survey (described in more detail in the Data section) may have prompted students to think more about the application process and encouraged them to seek out more information. By administering this survey in a random subset of schools (T1a, T2a, and T3a), we can measure how this increase in the salience of the applications, independent of the provision of additional information, changed students' knowledge and subsequent decisions.

\subsection{Empirical Strategy}

The primary conceptual difficulty in ascertaining the effect of information on student choices and subsequent outcomes is the typical non-random allocation of information. To overcome this difficulty, we randomly provided information to students and parents in some schools 
and not others. The resulting empirical estimation strategy is straightforward:

$$
Y_{i s}=\alpha+\beta_{1} \text { InfoStudents }_{s}+\beta_{2} \text { InfoStudentsParents }_{s}+\mathbf{W}_{\mathbf{i s}}^{\prime} \gamma+\varepsilon_{i s}
$$

where $Y_{i s}$ is the outcome for student $i$ in school $s$, InfoStudents $s_{s}$ is an indicator for whether school $s$ was a school in which only students and teachers received information (Group T1), InfoStudentsParents $s$ is an indicator for whether school $s$ was a school in which students, teachers, and parents were targeted to receive information (Group T2), $\mathbf{W}_{\text {is }}^{\prime}$ is a vector of binary variables representing the stratification bin from which school $s$ is drawn and student gender (see more details in the Data section), and $\varepsilon_{i s}$ is the idiosyncratic error, assumed to be independent across schools but allowed to be correlated within a school. Note that the treatment variables are mutually exclusive and not nested.

Our outcomes of interest trace the causal chain presented in Figure 1 above. We test for the effect of the intervention on a student's self-reported receipt of information. Second we test for changes in the selection process and self-reported priorities. Third, we test for the impact on students' official application choices. Fourth, we test for any intervention induced changes in students BECE scores. Fifth, we look for effects in the characteristics of schools to which students were admitted. Finally, we test whether the intervention affected secondary school matriculation outcomes. We measure these outcomes using a mix of selfreported and administrative data. All self-reported data are from the half of study schools, equally divided among treatment groups, in which we conducted a baseline survey to ensure that we were not conflating priming students to think about their choices with providing information. For estimates with administrative data, we use the entire sample, testing for the differential impact of being surveyed.

To address concerns about multiple hypothesis testing, in addition to testing individual outcomes, we estimate the effects of the program on categories of outcome variables, following the mean effects methodology of Kling et al. (2007). Each family of outcomes represents a set of related measures following our theory of change (see more details in Subsection 6.4) 


\subsection{Sample Selection}

We selected our sample from the universe of government JHSs listed on the Ghana Education Management Information System (EMIS) school roster. To be eligible for the sampling frame, a school had to be located in Ashanti, include all junior high school grades (JHS1 through JHS3), have at least one student qualify for secondary school admission in 2014, and be between the fifth and ninety-fifth percentile of JHS3 cohort size in Ashanti. Out of the 30 districts in Ashanti, we excluded one where we piloted the intervention and another with only 5 JHSs. We randomly selected 22 districts out of the remaining 28 for the study. ${ }^{17}$ These selected districts contained 1024 eligible JHSs.

From this sampling frame, we randomly selected 900 schools to participate in the study. We stratified our random assignment of treatment arms by district, ensuring that we had at least one school assigned to each treatment arm in each district. Some schools had more than one section, or stream as they are known in Ghana, of JHS3. For these schools, we randomly selected a single stream to both survey and treat, returning to the same stream for follow-up visits. We describe our survey-collected and administrative data in the next two subsections.

\subsection{Data}

Our study relies on both hand collected survey data and administrative data. In this subsection we describe both.

We collected data directly from students in two rounds of surveys, from parents or guardians in another round, and from an informed member of the students' household in the final round.

In January 2016, near the start of term 2 of the 2016-2017 school year, we conducted the baseline student and head teacher data collection in the 450 survey schools, 150 in each treatment arm. The student survey asked questions about demographic characteristics of

\footnotetext{
${ }^{17}$ We limited the study to 22 districts to reduce travel costs for the intervention.
} 
the students and their families, their previous educational experiences, knowledge of the application procedures and secondary schools, anticipated application choices, and educational and career ambitions. We also asked for contact information for their parents, older siblings with mobile phones, and other individuals who might know about their schooling outcomes in the future. ${ }^{18}$

After the baseline, enumeration teams administered the intervention to the students or students and parents based on the school's treatment status.

In March of 2016, near the end of term 2, after students had received the intervention and submitted their choices to the CSSPS, we returned to the same schools to conduct the JHS follow-up. We attempted to talk to the same students asking similar questions as the baseline. We used our collected contact information to survey via phone a random sample of 20 parents per school. The questions we asked were similar to those in the student JHS follow-up.

In April 2017, during what should have been the second term of secondary school for students progressing through school on pace, we again contacted students' households based on our collected contact information. In this round, the secondary school follow-up, we asked questions about the student's current schooling or other activities if not enrolled and when the student matriculated or dropped out of schooling. In contacting individuals for this round, we sought to speak with a member of the student's household who knew about the student's current schooling or working activities. This individual was most often the parent, older sibling, or the student themselves.

We used administrative data both to create the booklet and learn about student outcomes. For the booklet, the CSSPS secretariat provided three prior years of admission scores at the school-program level. The average of these three years appears in the booklet. The West African Education Council provided data on WASSCE pass rates at the school level, which we also included in the booklet.

\footnotetext{
${ }^{18}$ Because of the high incidence of child fostering in Ghana, we asked for the contact information of parents or guardians and treated them equivalently. For simplicity, we refer to them as parents throughout this paper.
} 
For student level outcomes, for all students in Ashanti who completed the CSSPS process we have their name, JHS name, four selected school-program pairs, BECE identification numbers, BECE scores, and the secondary school to which they were admitted. We use their BECE identification numbers to match students across the CSSPS and survey data. We match the remaining students using their names and JHS names, for those with errors in self-reported BECE IDs. We further combined the historical BECE admissions data and WASSCE pass rates to calculate a school-level value added measure. For each SHS, we use the school's residual from a regression of the BECE mean and BECE 5th percentile on the WASSCE pass rate. ${ }^{19}$

To implement our multiple hypothesis testing robustness check, we rescale each of the variables to have a mean of zero and a standard deviation of one. We then make all variables go in the same expected direction by multiplying a subset by negative one when necessary. Then within each category, we take the average and rescale this average to have a mean of zero and a standard deviation of one. This second rescaling of the averge allows us to interpret the magnitudes of the estimated effects in terms of standard deviations.

Figure 6 displays a timeline of fieldwork and student activities. We use these multiple collection rounds to measure changes in information, preferences, and beliefs and to assess whether information changes choices and eventual outcomes.

[Figure 6 about here]

Table 1 contains selected summary statistics and demonstrates baseline balance across the three arms. Of particular note in the summary statistics are parents' education levels-only about 40 percent of fathers and 23 percent of mothers have education beyond JHS with about 12 percent of each not having any formal education. Therefore, most of our sample are first generation secondary school students and cannot rely on previous parental experience with secondary school admissions. Such households could find the process especially daunting.

\footnotetext{
${ }^{19}$ On average, Option 3 schools have the highest value added, followed by Option 2, and Option 1. Private schools (Option 5) on average have value added between Options 1 and 2. All four distributions have substantial common support with the exception of some remarkably low value added estimates for some private schools.
} 
[Table 1 about here]

\section{Results}

Recall the causal chain outlined in Section 3.2. We address each of these steps in turnreceiving information, using and internalizing information, stating choices, taking the BECE, CSSPS admissions, and matriculation. As we described in the previous section, some outcomes rely on the survey sub-sample of 450 schools and others use administrative data over the full 900 school sample. In Sections 6.1 through 6.6 we use the largest sample possible. In Section 6.8 we show that the effects of the intervention on the administrative data outcomes are not differential by whether students completed the baseline survey.

\subsection{Receipt of Information}

Students received our intervention based on implementation tracking sheets and students' self-reports. At each treatment school an average of 30 students attended the workshop, received the booklet, and watched the video. In the parent treatment arm, 16 parents on average attended the parent workshop and watched the video.

Table 2 contains results of Equation 1 as a linear probability model with whether, during the first student follow-up, students reported having seen a booklet of school choices or a video about the school choice process. Recall from Equation 1 that the two treatment arms in which respondents received additional information are mutually exclusive and considered as separate regressors. Being in either the treatment that targeted only the students, i.e. Student Info, or the treatment that targeted both the students and parents, i.e. Parent Info, increased the likelihood that a student reported having seen a booklet with information about the school choices and the school choice process by about 14 percentage points (column 1). Over 82 percent of the control group also reported having seen a booklet. This could have been the GES booklet or our booklet borrowed from a friend. The video clearly left a very 
strong impression on students, increasing the likelihood that students reported having seen a video with information on the school choice system by over 76 percentage points (column 2). Fourteen percent of the control group also reported having seen a video. This could be a combination of being mistaken or having seen a previously produced CSSPS video that explained why the CSSPS was used but did not provide guidance on navigating the process. In both cases we fail to reject that the student only or student plus parents intervention had similarly sized effects. ${ }^{20}$

[Table 2 about here]

\subsection{Use of Information}

We next test whether students used the booklet as an information source. Students were asked where they got information about the academic quality of secondary schools, selecting as many information outlets as relevant. Based on the results in Table 3, in both treatment arms, students increased the likelihood that they used a booklet for academic information by about 17 percentage points (column 1). Even though 82 percent of the control group (Table 2) reported having seen a booklet, only 21 percent reported using a booklet for information, and our intervention almost doubled this likelihood. Students in treatment schools were less likely to report that they received information from traditional media (column 2), the internet (column 3), other people (column 4), or another source (column 5). In all but one case we fail to reject that the point estimates are the same across the two treatment arms and in almost all cases the point estimates on each treatment are different from 0 . We reject equality at the 10 percent level for the decline in relying on other people (column 4).

[Table 3 about here]

\footnotetext{
${ }^{20}$ Based on data collected in the parent follow-up and analyzed in Ajayi, Friedman, and Lucas (2017), parents in both treatment arms were about 11 percentage points more likely than the control group to report having seen a booklet. Parents in the parent treatment were further about 10 percentage points more likely than control parents to report having seen a video.
} 
In addition to information sources changing, parents were more likely to be involved in the process, another aspect our intervention highlighted. Our booklet encouraged students and parents to jointly consider options and our video modeled such a conversation. Over 75 percent of parents were already involved, and the intervention increased this likelihood by about 5 percentage points (Table 3, column 6).

The importance of parents in the process was echoed by parents themselves, but only when they were engaged with information directly (Ajayi, Friedman, and Lucas 2017, Table 2). In contrast to the students' responses that parents in both arms were more likely to be involved in the process, analysis presented in Ajayi, Friedman, and Lucas (2017) indicates that parents were only statistically more likely to report being involved when they were directly targeted for information-8 percentage points more likely to report providing help in the selection process and 6 percentage points more likely to be able to report students' selections.

The next step we examine is whether this use of information and parental involvement adjusted what students reported to value in schools. Table 4 shows that the treatment shifted the attributes that students found important towards the information in the booklet. Relative to the control group, students in the student information arm were more than twice as likely (3 percentage point increase on a base of 3 percentage points) to say that admissions chance was the most important (column 1). Students in treatment schools were also more likely to say the most important factor to consider was distance from home (column 2). ${ }^{21}$ These changes represent increases of 77 to 83 percent relative to the control group. Students in student only treatment schools were statistically less likely to consider how the school might affect future success (column 3). Students in the parent treatment arm were less likely to consider the overall reputation of the school (column 4). Students in both arms decreased their consideration of the discipline features of the school (column 5). Neither discipline nor reputation were covered in the booklet. The most important consideration for

\footnotetext{
${ }^{21}$ We did not provide distance from each JHS to each secondary school, instead we included information about the district and neighborhood of each secondary school, included a list of schools sorted by district, and mentioned the catchment option for students interested in staying close to home.
} 
all arms continued to be academic quality (column 6). We provided data on this margin, but it did not affect students' prioritization of this school feature. Overall, students in the treatment arms increased the likelihood that they selected schools based on an attribute we included in the booklet.

[Table 4 about here]

\subsection{Application Choices}

The changes in student's stated preferences were reflected in their choice behavior. For these outcomes we have administrative data from the CSSPS.

Table 5 contains estimates of the effect of treatment on various characteristics of students' official choices. Consistent with distance being a primary consideration, students were 4 percentage points more likely to apply only to schools in Ashanti (column 1). ${ }^{22}$

Recall in the analysis above that students in treatment schools were more likely to state that they considered their admission chances in selecting schools. In columns 2 through 5, we estimate the effect of our treatment on the reported mean BECE score of admitted students from the booklet, for each listed choice. Consistent with being concerned with admissions chances, all point values are negative-indicating schools with slightly lower admissions standards according to the booklet. We find these point values statistically different from 0 for choices 2 through 4 for the parent arm (columns 3 through 5). For choices 2 and 4, students applied to schools with 0.05 to $0.06 \mathrm{SD}$ lower historical BECE mean scores.

In columns 6 and 7, we test whether students on average applied to schools with higher WASSCE pass rates or value added and find statistically insignificant point values across both measures. ${ }^{23}$ While the intervention was designed to shift students away from schools

\footnotetext{
${ }^{22}$ Students were also 1 percentage point more likely (off a base of 93 percent) to select at least one school in Ashanti (results not presented).

${ }^{23}$ This is similarly statistically insignificant for each choice separately (results not presented). Because of an agreement with our data providers, the booklet did not present measures of value added. In workshops we encouraged participants to think about WASSCE pass rates relative to incoming BECE scores. We calculated value added using the WASSCE and BECE data from the booklet (see Data Section for more details).
} 
with bad WASSCE outcomes, these findings are consistent with students not changing (or perhaps decreasing) their value of the school's contribution to their future success. ${ }^{24}$

[Table 5 about here]

\subsection{The BECE}

A student's admission to secondary school depends on the combination of his BECE score and his listed choices. The intervention was not designed to alter the likelihood that students took the BECE or the effort they put into preparing for and taking the exam. Nevertheless, the extra information we provided students could have changed this behavior. We test for this behavior change in this subsection and present the results in Table 6.

We find that the intervention did not change the likelihood that a student took the BECE as scheduled (column 1). Further, the intervention did not change students' BECE scores (column 2). ${ }^{25}$

[Table 6 about here]

Given the lack of effect on selection into the BECE or a student's BECE score, any changes in admissions and matriculation are the result of changes in choices and not test scores or selection into the test.

\footnotetext{
${ }^{24}$ The Appendix contains additional choice outcomes. Students in the student information only arm were 1 percentage point more likely to list their choices in descending order of BECE booklet means (p-value $<0.1$, the control group base was 10 percent). The treatment did not affect the likelihood that students listed choices by descending booklet BECE 5th percentile or WASSCE pass rate (Table A1). By virtue of arbitrary page breaks, some secondary schools may have been more salient than others. The treatment did not change the number of choices that students listed that happened to appear at the top of a page (Table A2). Students in the parent information treatment listed 0.06 more schools from the first page of the GuIIDE booklet, the first 14 Option 1 (least selective) schools in alphabetical order. The average control group student listed 0.55 of these schools (Table A2).

${ }^{25}$ Other observable and self-reported measures of effort or aspirations are similarly unchanged by the intervention-reported absences, present on the day of the follow-up, aspire to at least complete secondary school, or aspire to pursue a university degree (results not presented).
} 


\subsection{Admissions}

As shown above, the intervention changed who participated in students' application processes, what they valued in schools, and their application behaviors. In this sub-section we test whether it changed their CSSPS admissions. Recall that the intervention did not affect students' BECE scores, therefore the results that follow are due to changes in choices not changes in test scores.

Table 7 shows that the treatment did not change the likelihood that a student was admitted to secondary school (column 1) or admitted to a school from their choice list (column 2). ${ }^{26}$ The point values are small, 1 to 3 percentage points, and statistically insignificant. About 53 percent of students were admitted to a school on their choice list with an additional 31 percent admitted to a school that they had not listed. Across both the treatment and control group, about 20 percent of students were admitted to their top choice school, 14 percent to their second choice school, 11 percent to their third choice school, and 9 percent to their fourth choice school. In column 3, we show that our intervention did not change this probability for Choice 1, with similar statistically insignificant effects for other choices.

\section{[Table 7 about here]}

We next test whether the intervention changed the characteristics of the school-program pairs or schools to which students were admitted (Table 8). Note this table is limited to students who were admitted to a school, which as shown in Table 7 is not differential by treatment status. Students were 4 percentage points more likely to be admitted to a school in Ashanti in the intervention that included parents (column 1). We can additionally look at the booklet-provided characteristics for students admitted to schools in Ashanti. Students were admitted to less selective schools by about 0.05 to 0.07 standard deviations (SD), based on the BECE mean presented in the booklet (column 2). Yet, these schools had equal value

\footnotetext{
${ }^{26}$ Column 1 includes students with sufficiently high BECE scores for secondary school admission who were placed arbitrarily by the CSSPS into a school with empty seats because all of their selected schools were full.
} 
added in the student only arm and higher value added in the parent arm by 0.08 SD (column 3). We reject at the 10 percent level that these values are equal. ${ }^{27}$

[Table 8 about here]

\subsection{Matriculation}

Despite indications above that the intervention might have improved match quality due to students making more informed choices and being admitted to marginally higher value added schools, their matriculation decisions were unchanged (Table 9). For these results, we rely on outcomes as reported by informed household members during what should have been the student's second term of secondary school. Sixty percent of control group students were attending secondary school at that time. Students in both treatment arms were no more likely to be attending secondary school (column 1). ${ }^{28}$ Further, conditional on attending school, they were no more likely to have started within the first six weeks of school, approximately on time in the Ghanaian context (column 2). Only 44 percent of students attending secondary school in the control group started within the first six weeks. They were no more likely to be attending the secondary school to which they were admitted by the CSSPS (column 3) or attending secondary school in Ashanti (column 4). Therefore, by revealed preference, student matches did not appear to have improved.

\section{[Table 9 about here]}

\footnotetext{
${ }^{27}$ Students are admitted to school-program pairs, not simply schools. Our administrative data does not contain the program for students who are admitted to a school-program outside of their choice list. For those students admitted to a school in their choice list we can re-estimate columns 2 and 3 for the school-program. The results are similar (the intervention caused a 0.07 to 0.09 SD decrease in the BECE of the admitted school-program pair, $\mathrm{p}<0.1$ and $\mathrm{p}<0.05$ respectively, and a $0.10 \mathrm{SD}$ increase in school-program value added for the intervention that included parents, $\mathrm{p}<0.01$.)

${ }^{28}$ Some of the students who were not attending secondary school in this second term might still enroll and complete school on a delayed schedule. Duflo et al. (2017) found that 47 percent of qualified students who had not yet enrolled in secondary school as of January (early term 2) of what should have been their first year completed secondary school within seven years. Secondary school typically lasts 3 years.
} 


\subsection{Multiple Hypothesis Testing}

Given the richness of outcomes we collected via survey or from administrative data, one concern could be erroneous discoveries due to testing multiple hypotheses. In Table 10, we group our outcomes into families based on the steps in the causal chain appearing in Figure 1 above. The exact variables that make up each family of outcomes are listed in detail in the table notes. In column 1, the student information treatment and the parent information treatment interventions caused large, positive and significant effects of on a set of outcomes representing reported exposure to the treatment. Each intervention increased reported exposure by $1.8 \mathrm{SD}$. In column 2 , the two interventions increased the information sources and priorities index value by 0.3 to $0.4 \mathrm{SD}, \mathrm{p}<0.001$. Next, in column 3 , the intervention changed the application choices by $0.1 \mathrm{SD}$. In column 4 , as with Table 6 above, the intervention did not affect the BECE index value. In Column 5, the parent intervention affected the admissions outcome by $0.1 \mathrm{SD}, \mathrm{p}<0.001$, and a smaller and not statistically significant coefficient on the student-only information treatment. Finally, consistent with the findings in Table 9 above, in column 6 neither intervention affected matriculation. Therefore, Table 10 confirms the results presented in the previous tables. We plot each of these coefficients in Figure 7.

[Table 10 about here]

[Figure 7 about here]

\subsection{Heterogeneity}

Even though mean effects can hide important distributional effects of the intervention, in our intervention the effects appear to be largely homogeneous with a few exceptions noted below. For parsimony, we provide estimates in the appendix on the heterogeneity by family as presented in the previous section.

For outcomes that relied on administrative data, we first test whether students in the schools with the baseline survey, who could have been primed to think more carefully about 
their choices, have different outcomes than students in those schools without baseline surveys. The intervention did not differentially affect the application, BECE test, or admissions indices, the three outcomes that relied on administrative data (Appendix Table A3).

We further test for heterogeneous effects by gender. Girls reported being about 0.10 SD less exposed to the intervention in the two treatment arms, changed their information sources and priorities about $0.12 \mathrm{SD}$ less in the intervention that included parents, and show a marginal differential decrease $(0.06 \mathrm{SD}, \mathrm{p}<0.10)$ in the BECE index (Appendix Table A4, columns 1 through 4). Despite these changes along the causal chain, the interventions affect boys and girls equivalently in admissions and matriculation (Appendix Table A4, columns 5 and 6).

Households with more highly educated parents might have needed the intervention less as they could have been more familiar with the system. Alternatively, those households could have found a document written in English easier to navigate. Appendix Table A5 tests for differential effects based on whether at least one parent completed junior high school. The results support the former hypothesis - households with more highly educated parents reported lower levels of exposure (by about 0.15 SD, Appendix Table A5, column 1). Across the other families of outcomes, the only other statistically significant difference is that students in highly educated households in the intervention that included parents changed their application decisions by 0.09 SD less (columns 2 through 6).

We additionally test for heterogeneity by BECE score, as this intervention might have had a different salience for students at different places in the test score distribution. Students with higher BECE scores in the intervention that included parents were less likely to report being exposed (-0.09 SD, $\mathrm{p}<0.1)$ and had a marginally higher value of the matriculation index (0.06 SD, p<0.1) (Appendix Table A6).

We finally test for differential effects by the number of secondary schools within $10 \mathrm{~km}$ of a student's JHS. The average student had 13 schools within 10km of their secondary school. For students in the intervention that only targeted students, both the exposure and BECE 
indices were decreasing in the number of schools $(-0.007 \mathrm{SD}, \mathrm{p}<0.05$, and $-0.009 \mathrm{SD}, \mathrm{p}<0.05)$ respectively (Appendix Table A7).

\section{Discussion}

The motivation for this research was to reduce inefficiencies and wasted resources at both the household and education sector level that resulted from students ex post sorting. While choice and admissions outcomes changed, the potentially more important matriculation outcomes did not. Below we set out a number of potential hypotheses as to why improved information did not affect those outcomes based on data previously discussed and in-depth interviews with households approximately one year after the conclusion of the intervention.

First, we can rule out the possibility that people did not receive or understand the material or the process. We provided evidence above that intermediate outcomes (i.e., choices and priorities) changed. In in-depth interviews, respondents mentioned that often "parents are too naive" and blame others when "it was their own mistake." One mentioned that she studied the booklet "so when it was time for selecting, I knew what I was doing." Students also noted how important it was to "know your standard and academic performance and compare it with the schools' acceptable grades."

A second concern is that we saturated the geographic area with booklets - all students were effectively treated because they had a friend or relative in a treatment school who let them borrow a booklet. Our 22 study districts contained 1,138 JHSs, and 600 of them, 43 percent, received booklets. As with the prior concern, the possibility of saturation also seems unlikely since we were able to discern differences by treatment status for the intermediate outcomes.

A third related concern is that all treated students applied to the same narrow set of schools and thus increased the selectivity of these schools, leaving no room for improvements in admission outcomes. We explore this possibility by analyzing whether students in treated

schools were more likely to apply to schools more prominently listed in the booklet or to the 
same schools as their classmates. Although students in the parent treatment arm were more likely to apply to schools listed on the first page of the booklet, they were no more likely to apply to the same schools as their classmates (Appendix Table A2). The estimated treatment effects in regressions analyzing the number of classmates applying to the same choice are small and negative, indicating that if anything, the intervention encouraged students to apply to a slightly more diversified set of choices within schools.

Fourth, our intervention may not have moved intermediate outcomes enough to change matriculation decisions. Some students may not have been swayed by our intervention because it was too late. Despite working with schools to time the workshops close enough to the decision to be salient, but not too early, we may have provided information too late. According to our in-depth interviews, several respondents reported "I saw the book but my mind was already made up," "I chose the school I already had in mind," and "the schools that were in my mind, I was determined to attend one of them."

Fifth, while information was a constraint for some households, other considerations might have been paramount for matriculation decisions. For students who either did not matriculate or matriculated to a school to which they were admitted, fewer than $1 \%$ stated that disliking the placement was the key consideration - the primary way in which information might improve outcomes. For students not in school during what should have been the first year of secondary school, 76 percent said that fees were the most important barrier. In the qualitative work, students mentioned concerns about schools being "too expensive for you to afford" as a reason for eventual non-matriculation. Even though all government schools had the same official fee schedule, 39 percent of households whose student was attending a school other than the one to which he was admitted cited cost as a factor. In the booklet, we provided the officially approved fees for government schools, but schools often charged additional fees, which were allowed as long as they were "reasonable." Therefore, even though the booklet contained the official fee schedule, students could have encountered unanticipated costs at the school to which they were initially admitted, causing them to seek out 
an alternative. Alternatively, households could have listed their choices in February subject to an existing budget constraint or a future expected windfall, but an unanticipated shock or lack of windfall between February and October could have altered their realized budget constraint.

Beyond fees, distance from home could have been an important factor. Even though distance was knowable and time invariant, the same unanticipated shocks to income could have altered preferences over distance. For students who were attending a different school than the one to which they were admitted, 24 percent cited distance as the reason for the school change. ${ }^{29}$ This movement towards home also appears in the data. Figure 8 presents the distribution of distances to admitted schools, attending schools (split by those to which students were and were not admitted), and schools listed for each choice. Overall, students attended schools closer to their JHSs than the ones to which they were admitted (grey dashed line of attending relative to solid black line of admitted). For students who deviated from their CSSPS admitted school, those schools were even closer to their JHS (the dotted blue line, which is above both the "Attending (All)" grey dashed line and the "Admitted" solid black line). Finally, students appear to be selecting schools of similar distances across all choices - the densities of the four choice lines are quite similar to each other.

[Figure 8 about here]

The distance between a students' JHS and her admitted school does predict whether she chose to attend that admitted school. Figure 9 shows the likelihood of attending the admitted school (solid dark line with circles), the likelihood of attending a school to which the student was not admitted (solid light line with squares), and the likelihood of not attending any school (dashed line with diamonds), by distance between the student's JHS and the admitted school. Each dot is the average within a $5 \mathrm{~km}$ bin, e.g. the dot at $5 \mathrm{~km}$ is for secondary schools 0 to $5 \mathrm{~km}$ away from the JHS. Those who were admitted to schools closer

\footnotetext{
${ }^{29}$ Almost all of the academic track secondary schools in our data have both a boarding and day option, therefore distance was not a strictly limiting factor when considering potential choices.
} 
to their JHS are substantially more likely to be attending that school, but the relationship is non-monotonic. Almost 70 percent of students admitted to a school within $5 \mathrm{~km}$ attend that school. Over 50 percent of students admitted to a school $5-10 \mathrm{~km}$ or $10-15 \mathrm{~km}$ of their JHS attend that school, as do students admitted to schools 25-30, 30-35, 80-85, and 85$90 \mathrm{~km}$ away from their JHS. ${ }^{30}$ As tested in Section 6.8, the effects of the intervention on admissions and matriculation do not vary by the density of available secondary schools. on students with more schools within 10kms (reported in Appendix Table A7). Taken together, it appears that while students are not consistently choosing only the closest schools, distance is an important determinant of whether and where a student attends.

In a low-resource setting with frequent unanticipated shocks, knowing school preferences in advance may be impossible. Households may have completed the CSSPS forms intending to adhere to the admissions, but an unanticipated shock could have prevented that realization.

\section{Conclusions}

As the increase in primary school enrollment and completion since the mid-1990s moves into the secondary school sector, and an increasing number of African countries move to make secondary school free, efficiently using available resources is crucial. To improve the efficiency in the transition between junior high and secondary school in Ghana, we provided students and parents with information about the available secondary schools and the centralized system that allocates students to schools. To test the effects of this information, we conducted a 900-school RCT, enabling us to compare outcomes across three treatment groups. For the 300 schools in treatment 1 , students alone received information. In the 300 treatment 2 schools, students and parents received information. In a final 300 schools, neither students nor parents received additional information. Based on both survey and administrative

\footnotetext{
${ }^{30}$ When considering proximate schools, most students have multiple choices. Forty-two percent have at least one school within $2 \mathrm{~km}$ of their JHS, the average student has 13 Option 1-3 schools within 10km, and 52 percent of students had 5 or more Option 1-3 scools within 10km of their JHS.
} 
data, we found that students and parents wanted and received our information. Further, the characteristics of the schools to which students applied marginally changed, and they were admitted to higher value-added schools. Nevertheless, the improved information did not improve education outcomes - students were no more likely to start school on time or enroll at all. Based on interviews with students after the intervention, many said that they remembered the intervention, especially the video, but that they had either already made up their minds or that they were constrained in their matriculation decisions by distance to schools or lack of resources. The former suggests an intervention earlier in the school year, while the latter points towards a larger issue in the school choice system. Therefore, while allowing universal school choice can benefit students of all socioeconomic backgrounds, those with fewer resources may continue to make constrained choices. 


\section{References}

Abdulkadiroğlu, A., P. Pathak, A. Roth, and T. Sönmez (2006). Changing the boston school choice mechanism. Working Paper 11965, National Bureau of Economic Research.

Ajayi, K. F. (2013). School choice and educational mobility: Lessons from secondary school applications in ghana. Institute for Economic Development Discussion Paper 259.

Ajayi, K. F., W. H. Friedman, and A. M. Lucas (2017). The importance of information targeting for school choice. American Economic Review 107(5), 638-43.

Allende, C., F. Gallego, and C. Neilson (2019, July). Approximating the equilibrium effects of informed school choice. Working Paper 628, Industrial Relations Section.

Andrabi, T., J. Das, and A. I. Khwaja (2017, June). Report cards: The impact of providing school and child test scores on educational markets. American Economic Review 107(6), $1535-63$.

Banerjee, A., S. Barnhardt, and E. Duflo (2015). Movies, margins, and marketing: Encouraging the adoption of iron-fortified salt. In Insights in the Economics of Aging, pp. 285-306. University of Chicago Press.

Banerjee, A. V., R. Banerji, E. Duflo, R. Glennerster, and S. Khemani (2010). Pitfalls of participatory programs: Evidence from a randomized evaluation in education in india. American Economic Journal: Economic Policy 2(1), 1-30.

Barrera-Osorio, F. and K. G. F. L. D. Deming (2020). Providing performance information in education: An experimental evaluation in colombia. Technical report, Mimeo.

Bobba, M. and V. Frisancho (2019). Perceived ability and school choices. TSE Working Papers 16-660, Toulouse School of Economics (TSE).

Corcoran, S. P., J. L. Jennings, S. R. Cohodes, and C. Sattin-Bajaj (2018, March). Leveling the playing field for high school choice: Results from a field experiment of informational interventions. Working Paper 24471, National Bureau of Economic Research.

Dinkelman, T. and C. A. Martinez (2014, MAY). Investing in Schooling in Chile: The Role of Information about Financial Aid for Higher Education. Review of Economics and Statistics 96(2), 244-257.

Duflo, E., P. Dupas, and M. Kremer (2017). The impact of free secondary education: Experimental evidence from ghana. Massachusetts Institute of Technology Working Paper Cambridge, $M A$.

Dupas, P. (2011). Do teenagers respond to hiv risk information? evidence from a field experiment in kenya. American Economic Journal: Applied Economics 3(1), 1-34.

Dustan, A. (2018). Family networks and school choice. Journal of Development Economics 134, 372-391. 
Dynarski, S., C. Libassi, K. Michelmore, and S. Owen (2018, December). Closing the gap: The effect of a targeted, tuition-free promise on college choices of high-achieving, lowincome students. Working Paper 25349, National Bureau of Economic Research.

Grenet, J., Y. He, and D. Kübler (2019, May). Decentralizing Centralized Matching Markets: Implications From Early Offers in University Admissions. Rationality and Competition Discussion Paper Series 158, CRC TRR 190 Rationality and Competition.

Hastings, J. and J. Weinstein (2008, November). Information, school choice, and academic achievement: Evidence from two experiments. Quarterly Journal of Economics 123(4), 1373-1414.

Hastings, J. S., C. A. Neilson, and S. D. Zimmerman (2012, August). The effect of school choice on intrinsic motivation and academic outcomes. Working Paper 18324, National Bureau of Economic Research.

Hoxby, C. M. and S. Turner (2013). Expanding college opportunities for low-income, highachieving students. Working Paper 12-014, Stanford Institute for Economic Policy Research.

Jensen, R. (2010, May). The (perceived) returns to education and the demand for schooling. Quarterly Journal of Economics 125(2), 515-548.

Kapor, A. J., C. A. Neilson, and S. D. Zimmerman (2020). Heterogeneous beliefs and school choice mechanisms. American Economic Review 110(5), 1274-1315.

Kirkeboen, L. J., E. Leuven, and M. Mogstad (2016). Field of study, earnings, and selfselection. Quarterly Journal of Economics 131(3), 1057-1111.

Kling, J. R., J. B. Liebman, and L. F. Katz (2007). Experimental analysis of neighborhood effects. Econometrica 75(1), 83-119.

Lai, F., E. Sadoulet, and A. de Janvry (2009, August). The adverse effects of parents' school selection errors on academic achievement: Evidence from the beijing open enrollment program. Economics of Education Review 28(4), 485-496.

Lucas, A. M. and I. M. Mbiti (2012, May). The determinants and consequences of school choice errors in kenya. American Economic Review 102(3), 283-88.

Mizala, A. and M. Urquiola (2013, JUL). School Markets: The Impact of Information Approximating Schools' Effectiveness. Journal of Development Economics 103, 313-335.

Neilson, C. (2019). The rise of centralized choice and assignment mechanisms in education markets around the world. Mimeo.

Ortega Hesles, M. E. (2015). School Choice and Educational Opportunities: The UpperSecondary Student-Assignment Process in Mexico City. Ph. D. thesis.

Pathak, P. and T. Sönmez (2008, September). Leveling the playing field: Sincere and sophisticated players in the boston mechanism. American Economic Review 98(4), 163652 . 


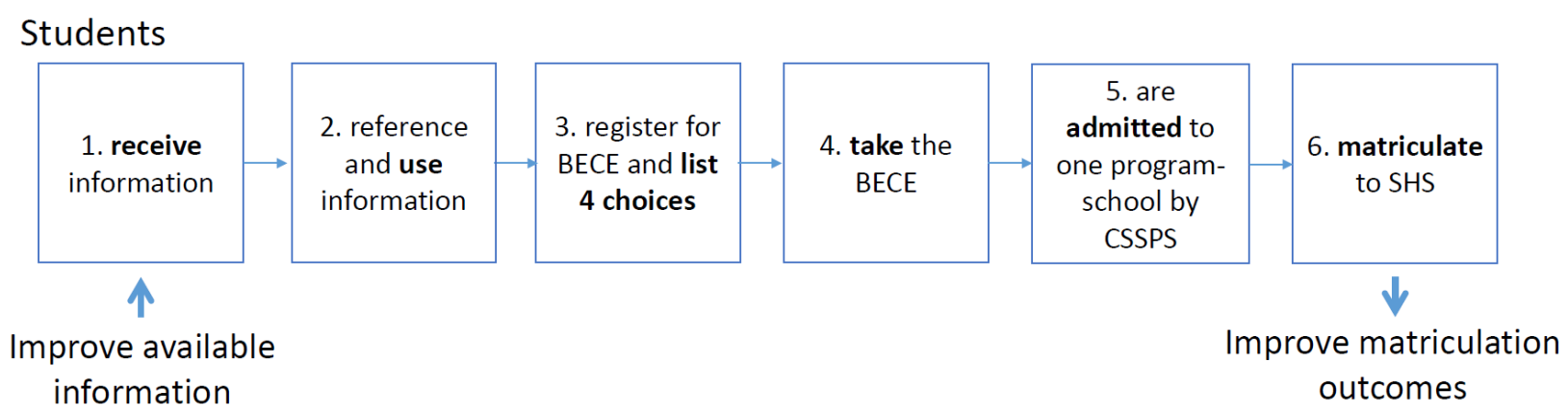

Figure 1: Theory of Change

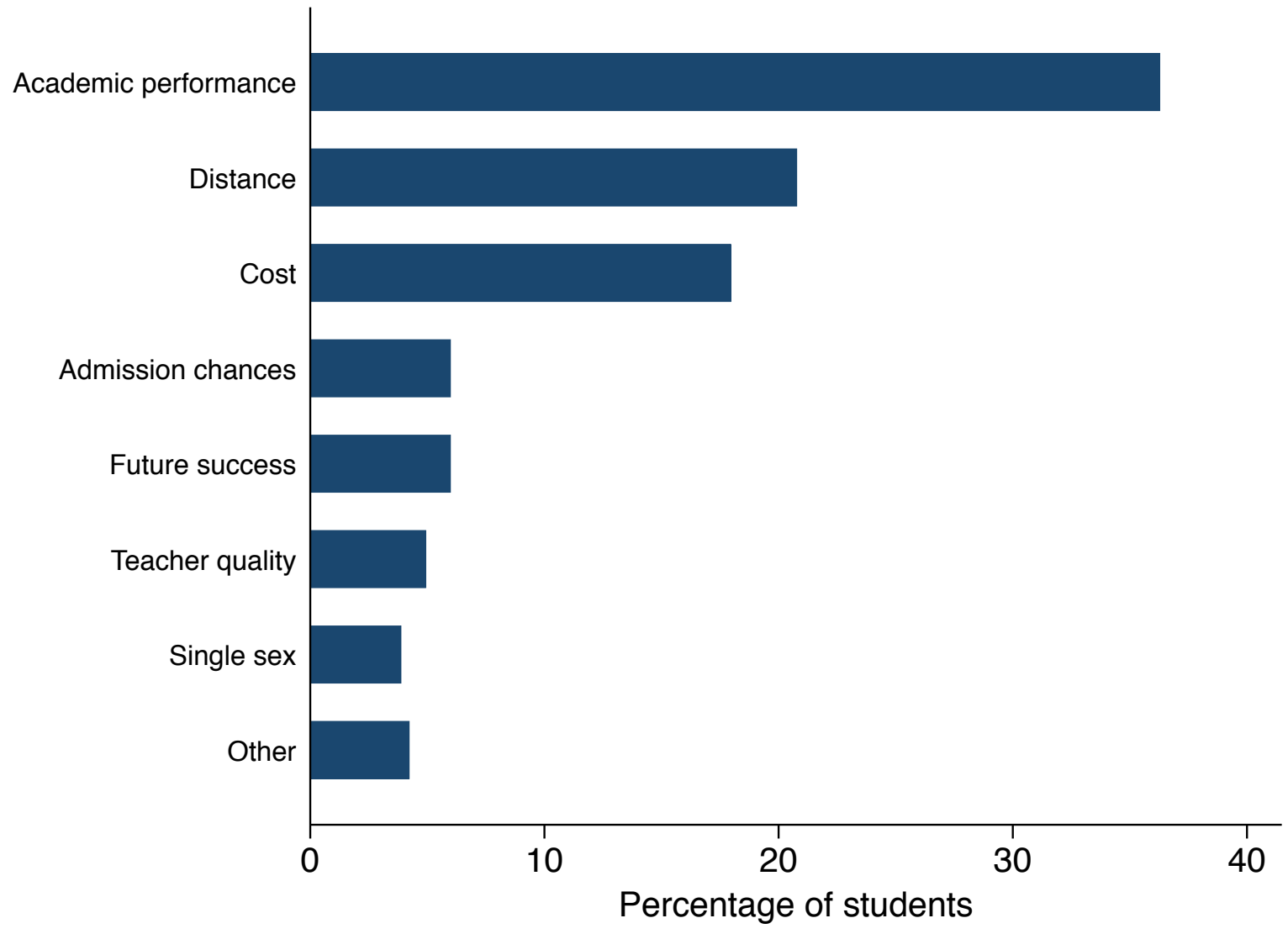

Figure 2: Most important characteristic for school selection 


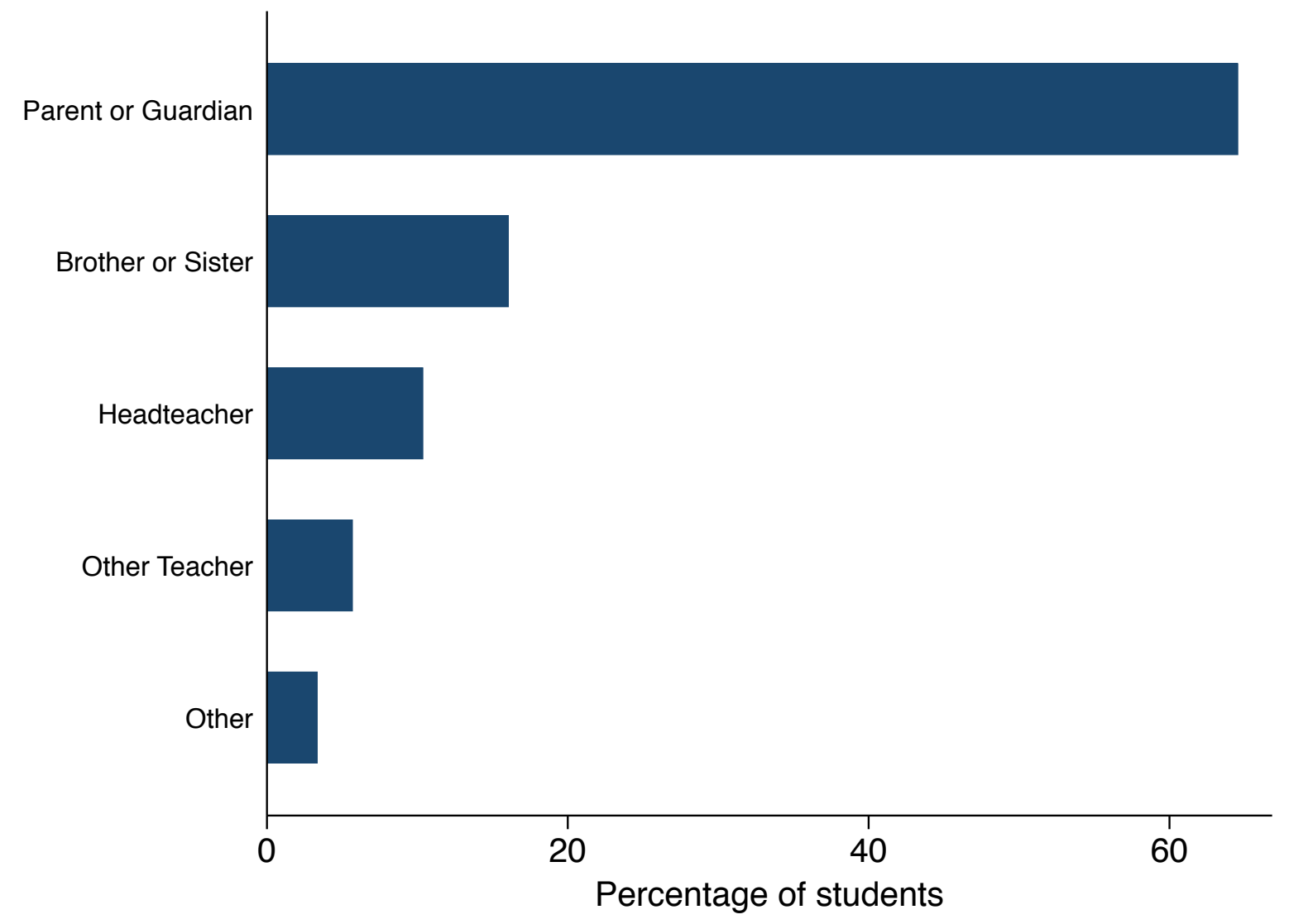

Figure 3: Most helpful decision maker 


\section{Senior High School Information Booklet}

Senior high school choices are important but many students choose schools they do not know much about and are then dissatisfied with their admissions outcomes. Making careful choices is one of the best ways to have a good senior high school experience.

\section{How it works:}

You will be selecting four choices from second cycle schools of different options. Each option contains a different set of schools.

\section{OPTIONS:}

Options 1, 2 \& 3: Public Senior High Schools

Option 4: Public Technical/Vocational Institutions

Option 5: Private Senior High Schools + Private Technical/Vocational Institutions

\section{You must:}

1. Choose four different schools.

2. Select a programme and an accommodation for each choice.

3. Remember that your choices:

- Can include up to four Option 1 schools

- Can include up to four Option $\mathbf{4}$ or $\mathbf{5}$ schools

- Can include up to two Option 2 schools

- Can include up to one Option 3 school

\section{How to make good senior high school choices:}

\section{What is important to you and your family?}

- Staying close to home? Only select schools in your region or district. If you want to stay within $16 \mathrm{~km}$ of your JHS, use the CATCHMENT AREA OPTION.

- Single sex or mixed? Some schools are mixed and some are girls or boys only.

- Boarding or day? Some schools offer both options but some offer only one.

- Programme type? Be sure to choose schools that offer your programme of interest.

\section{What was your raw BECE score (out of 600 ) on your mock exams?}

- Use the worksheet in this booklet to calculate it.

- Be sure to choose at least one school where you have a good chance of being admitted.

\section{Pick schools you would actually like to attend!}

- You can only list four choices, and most students do not get placed in their first choice, so every choice is important.

\section{List your choices in order of preference.}




\section{How to use this booklet:}

This booklet contains information on all senior high schools and technical/vocational institutes in Ashanti region, to inform you about your local options. You are free to select other schools outside this region if you would like.

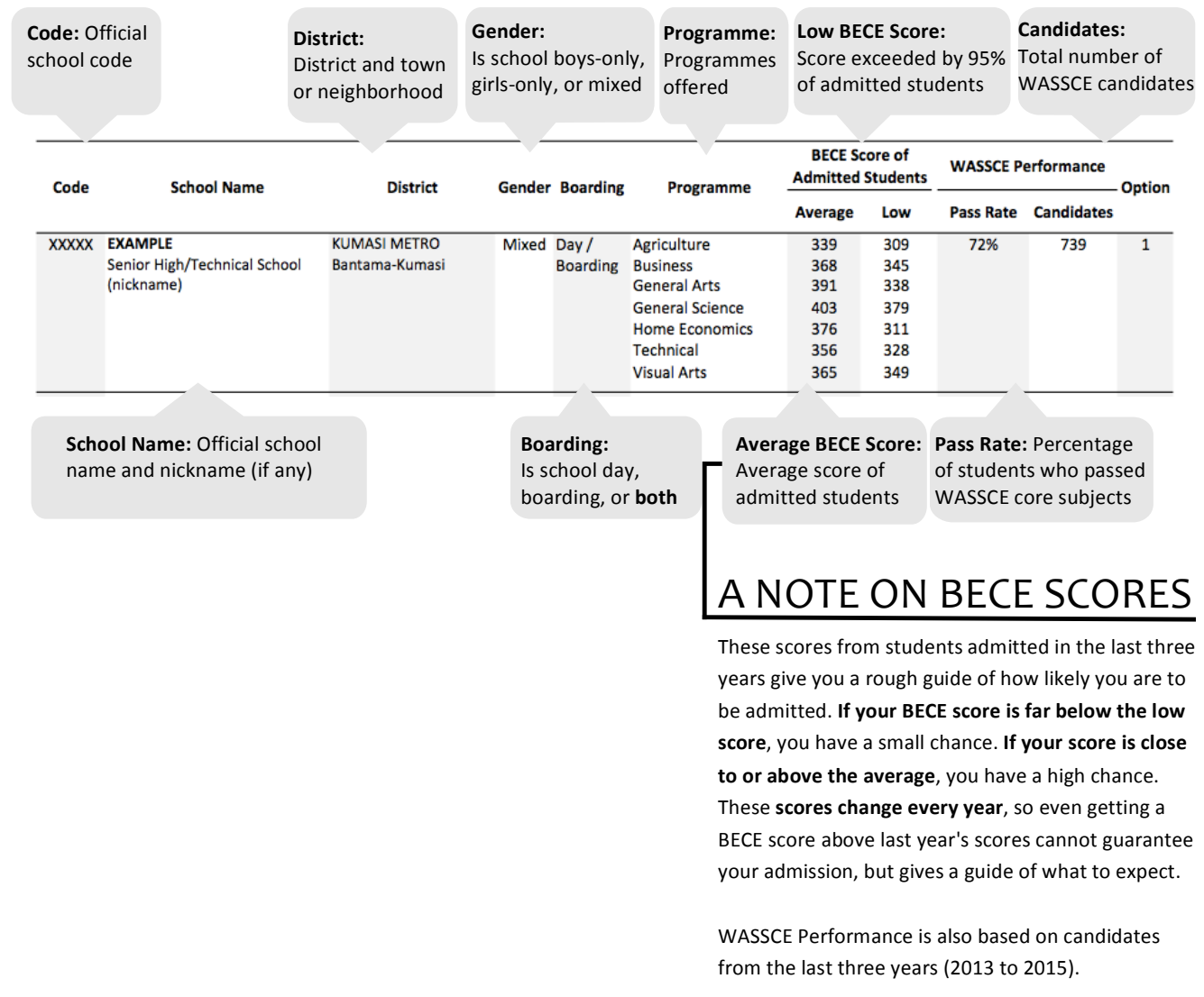

Figure 5: Sample Booklet Page 


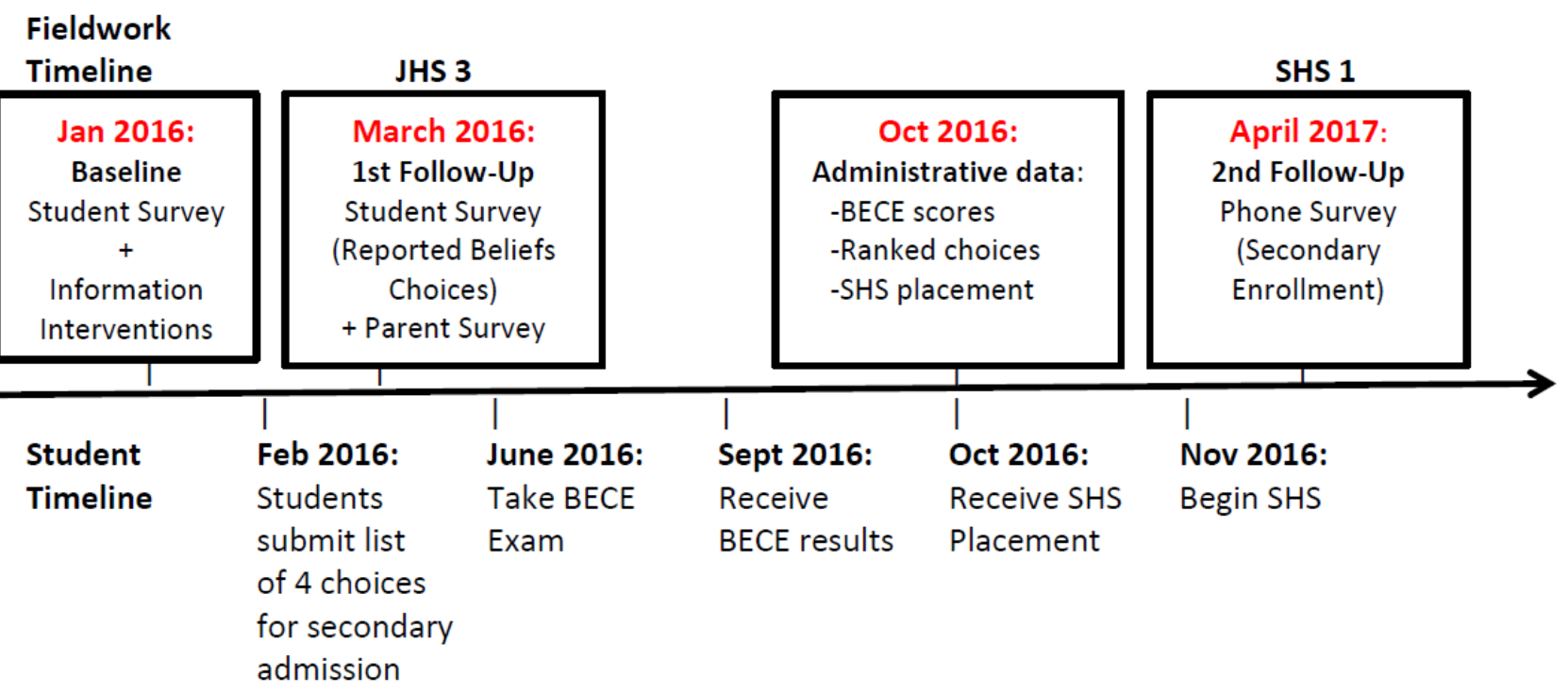

Figure 6: Study timeline 


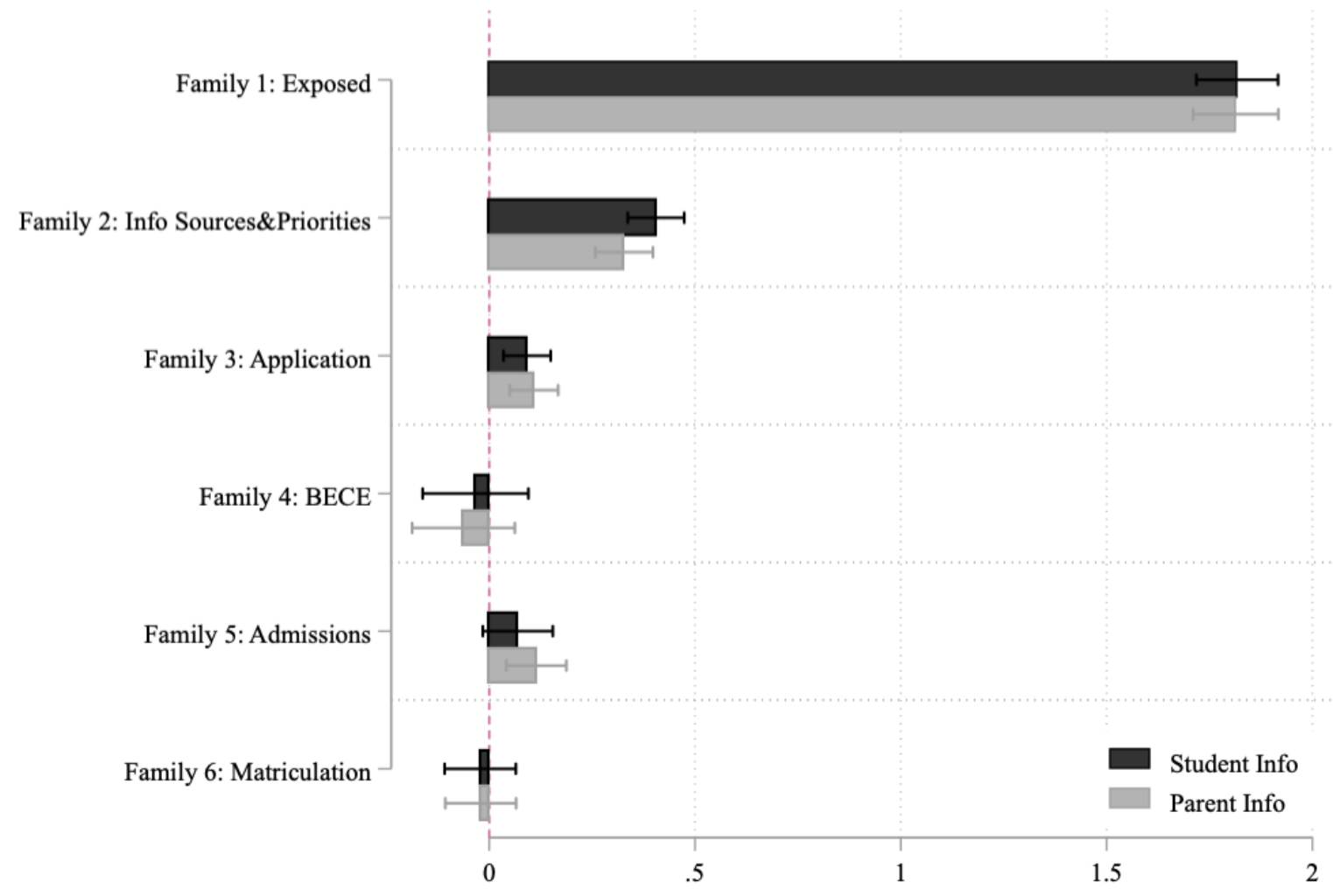

Figure 7: Effects by Steps in the Causal Chain

Notes: Figure presents coefficients from mean effects estimates on families of outcomes. Family 1: whether the student reported having seen the booklet and having seen the video (the outcomes in Table 2). Family 2: whether the student reported getting information from a booklet; whether they did not report getting information from radio/TV/Newspaper, the internet, other people, or other; and whether the student prioritized information in the booklet (distance, academic quality, and admissions chances) and not those not in the booklet (how affect future success, teacher quality or school reputation or facilities, discipline) (outcomes in Tables 3 and 4). Family 3: whether the student applied to only Ashanti schools, the reverse of the mean reported BECE scores in their 1st, 2nd, 3rd, and 4th choice schools, the mean WASSCE pass rate and value-added at all the schools to which they applied (outcomes in Table 5). Family 4: whether the student took the BECE and their BECE score (outcomes in Table 6). Family 5: whether they were admitted to any school, admitted to any of their choices, admitted to their first choice, admitted to a school in Ashanti, the reverse of the admitted SHS BECE mean, the admitted secondary school value-added, the reverse of the assigned program BECE mean, and the assigned program value added (outcomes in Tables 7 and 8). Family 6: whether they are currently attending secondary school, whether they started on-time, whether they are attending the school to which they were admitted, and whether they are attending a secondary school in Ashanti (outcomes in Table 9). All estimates control for gender and strata fixed effects. Confidence intervals adjust for clustering at the JHS level. 


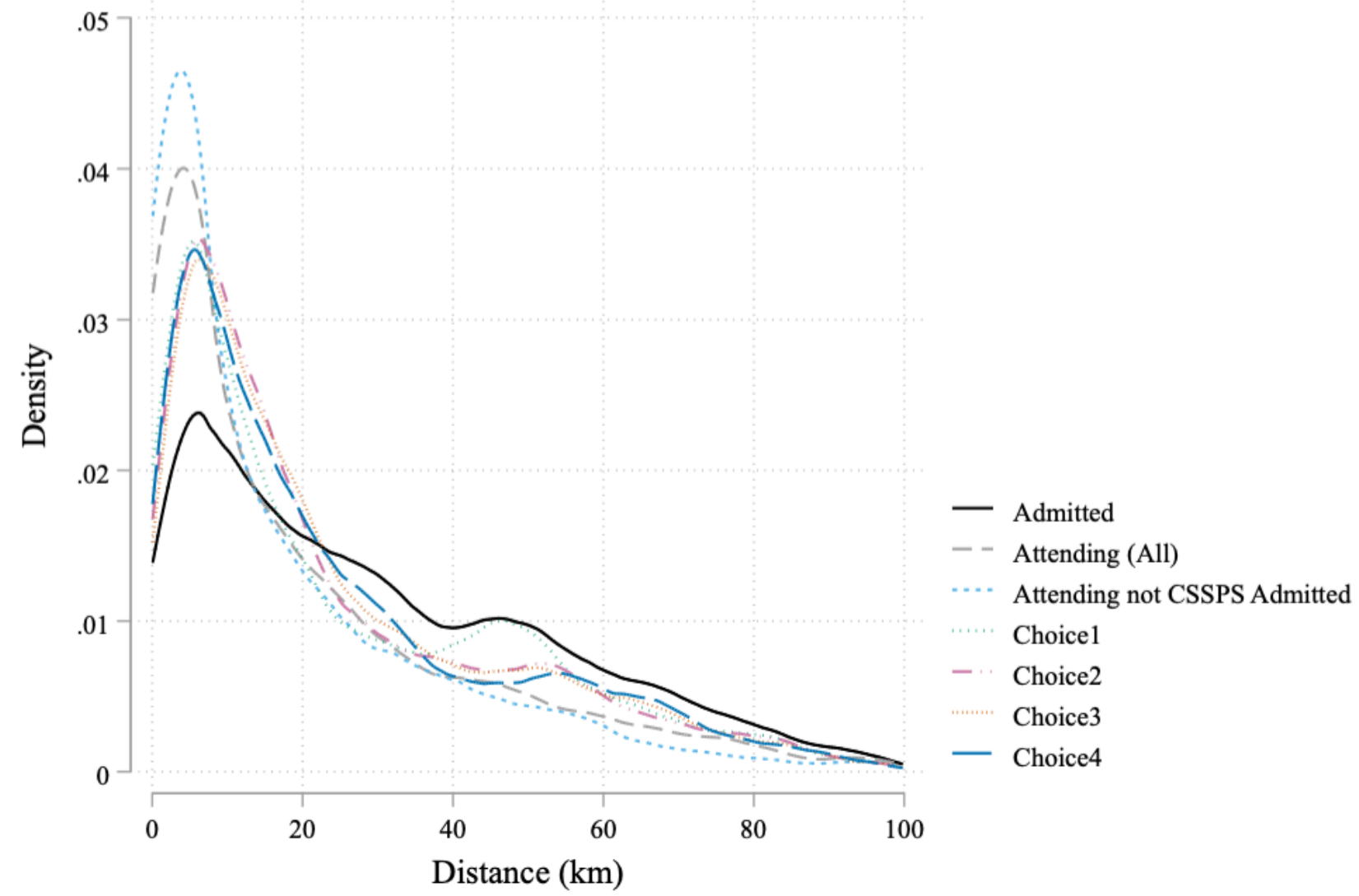

Figure 8: Distance Between JHS and Secondary School

Notes: Figure illustrates the distribution of distances between students' junior high schools and their admitted secondary schools, the secondary schools they are currently attending (split by those to which students were and were not admitted), and the secondary schools listed for each choice. 


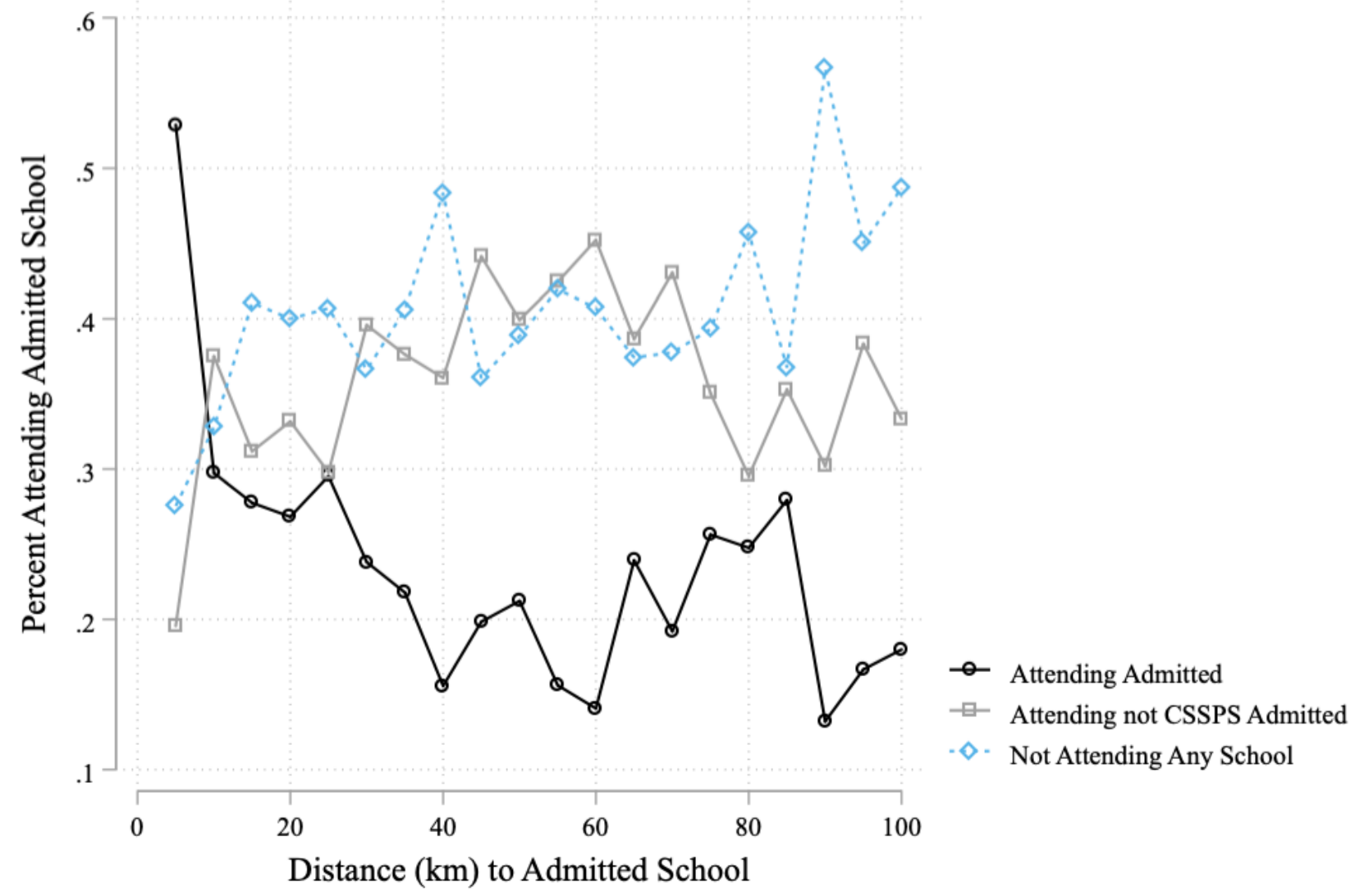

Figure 9: Matriculation and Distance

Notes: Figure shows the likelihood of students attending their admitted school, the likelihood of attending a school to which the student was not admitted, and the likelihood of not attending any school, by distance between a student's junior high school and their admitted secondary school. 
Table 1: Baseline Balance

\begin{tabular}{|c|c|c|c|c|c|}
\hline & $\begin{array}{l}\text { Student } \\
\text { Info } \\
(1)\end{array}$ & $\begin{array}{l}\text { Parent } \\
\text { Info } \\
(2)\end{array}$ & $\begin{array}{c}\text { Control } \\
(3)\end{array}$ & $\begin{array}{l}\text { p-value diff } \\
\text { (1) vs (3) } \\
\text { (4) }\end{array}$ & $\begin{array}{l}\mathrm{p} \text {-value diff } \\
(2) \text { vs }(3) \\
(5)\end{array}$ \\
\hline Female & $\begin{array}{c}0.43 \\
(0.50)\end{array}$ & $\begin{array}{c}0.43 \\
(0.50)\end{array}$ & $\begin{array}{c}0.44 \\
(0.50)\end{array}$ & 0.65 & 0.63 \\
\hline Age & $\begin{array}{l}15.93 \\
(1.44)\end{array}$ & $\begin{array}{l}15.81 \\
(1.42)\end{array}$ & $\begin{array}{l}15.81 \\
(1.43)\end{array}$ & 0.13 & 0.13 \\
\hline Days Absent & $\begin{array}{l}1.66 \\
(3.22)\end{array}$ & $\begin{array}{c}1.76 \\
(3.29)\end{array}$ & $\begin{array}{c}1.69 \\
(3.41)\end{array}$ & 0.53 & 0.83 \\
\hline Taken Mock BECE & $\begin{array}{c}0.50 \\
(0.50)\end{array}$ & $\begin{array}{c}0.49 \\
(0.50)\end{array}$ & $\begin{array}{c}0.52 \\
(0.50)\end{array}$ & 0.94 & 0.75 \\
\hline Expected BECE & $\begin{array}{l}11.60 \\
(4.77)\end{array}$ & $\begin{array}{l}11.55 \\
(4.82)\end{array}$ & $\begin{array}{l}11.57 \\
(4.82)\end{array}$ & 0.87 & 0.91 \\
\hline Believes CSSPS Fair & $\begin{array}{c}0.61 \\
(0.49)\end{array}$ & $\begin{array}{c}0.60 \\
(0.49)\end{array}$ & $\begin{array}{c}0.58 \\
(0.49)\end{array}$ & 0.79 & 0.43 \\
\hline Low Income & $\begin{array}{c}0.27 \\
(0.44)\end{array}$ & $\begin{array}{c}0.26 \\
(0.44)\end{array}$ & $\begin{array}{c}0.26 \\
(0.44)\end{array}$ & 0.73 & 0.74 \\
\hline Father Educated Beyond JHS & $\begin{array}{c}0.39 \\
(0.49)\end{array}$ & $\begin{array}{c}0.44 \\
(0.50)\end{array}$ & $\begin{array}{c}0.41 \\
(0.49)\end{array}$ & 0.05 & 0.49 \\
\hline Mother Educated Beyond JHS & $\begin{array}{c}0.23 \\
(0.42)\end{array}$ & $\begin{array}{c}0.24 \\
(0.43)\end{array}$ & $\begin{array}{c}0.23 \\
(0.42)\end{array}$ & 0.39 & 0.84 \\
\hline Father completed no school & $\begin{array}{c}0.12 \\
(0.32)\end{array}$ & $\begin{array}{c}0.10 \\
(0.30)\end{array}$ & $\begin{array}{c}0.12 \\
(0.32)\end{array}$ & 0.29 & 0.87 \\
\hline Mother completed no school & $\begin{array}{c}0.17 \\
(0.37)\end{array}$ & $\begin{array}{c}0.15 \\
(0.36)\end{array}$ & $\begin{array}{c}0.16 \\
(0.37)\end{array}$ & 0.29 & 0.64 \\
\hline Observations & 3631 & 3540 & 3617 & & \\
\hline
\end{tabular}

Notes: Columns 1-3: Sample means with standard deviations in parenthesis. Columns 4 and 5: p-values of differences based on standard errors adjusted for clustering at the JHS level.

Table 2: Receipt of Information

\begin{tabular}{lcc}
\hline & Seen Booklet & Seen Video \\
& $(1)$ & $(2)$ \\
\hline Student Info & $0.139^{* * *}$ & $0.779^{* * *}$ \\
& $(0.017)$ & $(0.018)$ \\
Parent Info & $0.153^{* * *}$ & $0.764^{* * *}$ \\
& $(0.017)$ & $(0.020)$ \\
\hline Student = Parent $p$-value & 0.08 & 0.48 \\
Observations & 11466 & 11456 \\
$R^{2}$ & 0.10 & 0.59 \\
Control Group Mean & 0.82 & 0.14 \\
\hline
\end{tabular}

Note: All outcomes from the first follow-up survey. These outcomes are based on student self-reports of whether they had seen a booklet/video about the secondary school application process. Each column represents one regression, which controls for gender and includes strata fixed effects. Standard errors adjusted for clustering at the JHS level appear in parenthesis, ${ }^{*} \mathrm{p}<0.1,{ }^{* *} \mathrm{p}<0.05,{ }^{* * *} \mathrm{p}<0.01$. 


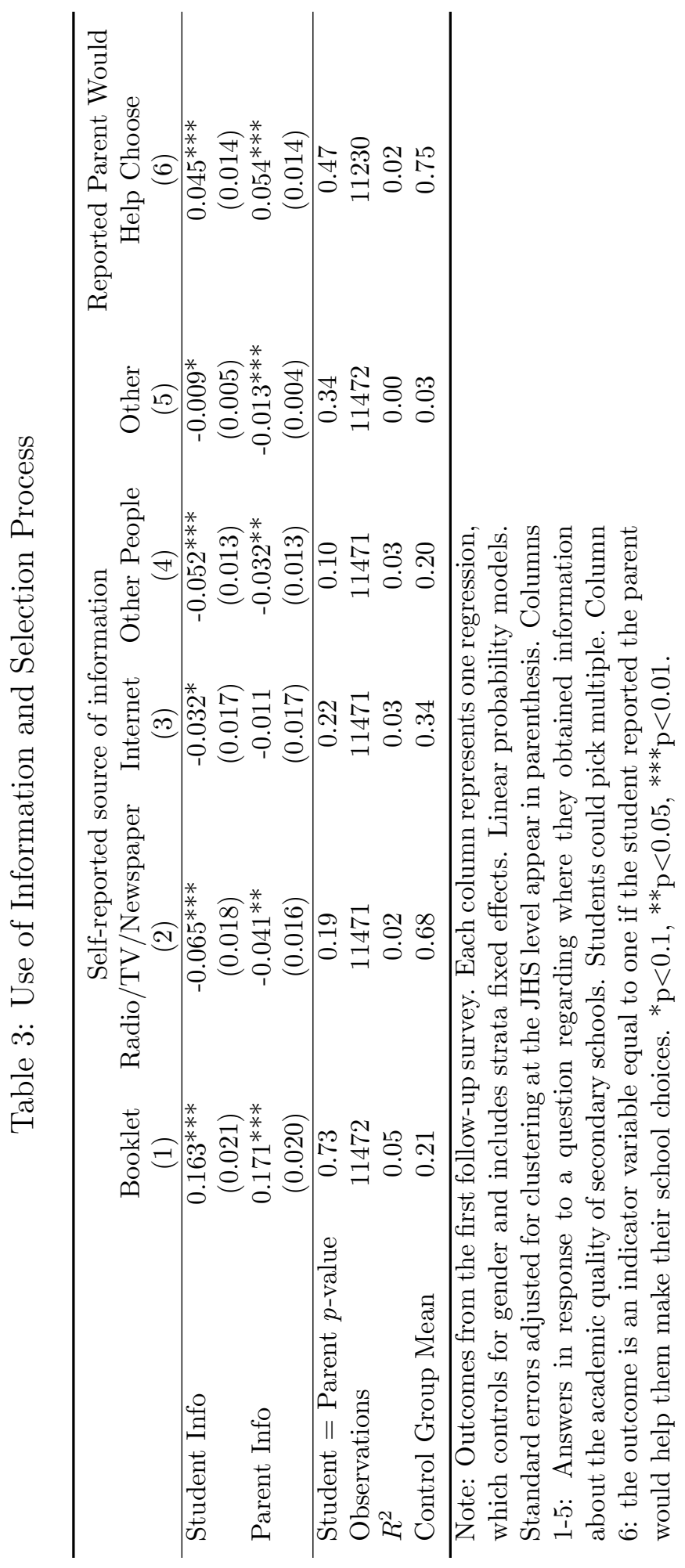




\section{Table 4: Stated Preferences-Most Important Factor in Selecting Schools}

\begin{tabular}{|c|c|c|c|c|c|c|}
\hline & $\begin{array}{l}\text { Admissions } \\
\text { Chance } \\
\text { (1) }\end{array}$ & $\begin{array}{c}\text { Distance } \\
(2)\end{array}$ & $\begin{array}{c}\text { Teacher quality or } \\
\text { How Affect } \\
\text { Future Success } \\
(3)\end{array}$ & $\begin{array}{c}\text { School Reputation } \\
\text { or Facilities } \\
\text { (4) }\end{array}$ & $\begin{array}{c}\text { Discipline } \\
\quad(5)\end{array}$ & $\begin{array}{c}\text { Academic } \\
\text { Quality } \\
(6)\end{array}$ \\
\hline \multirow[t]{2}{*}{ Student Info } & $0.031^{* * *}$ & $0.036^{* * *}$ & $-0.038^{* * *}$ & -0.015 & $-0.009^{*}$ & 0.005 \\
\hline & $(0.009)$ & $(0.007)$ & $(0.010)$ & $(0.009)$ & $(0.005)$ & $(0.021)$ \\
\hline \multirow[t]{2}{*}{ Parent Info } & $0.009^{*}$ & $0.039^{* * *}$ & -0.013 & $-0.020^{* *}$ & $-0.011^{* *}$ & 0.013 \\
\hline & $(0.005)$ & $(0.007)$ & $(0.011)$ & $(0.009)$ & $(0.005)$ & $(0.019)$ \\
\hline Student $=$ Parent $p$-value & 0.02 & 0.75 & 0.01 & 0.52 & 0.72 & 0.65 \\
\hline Observations & 11454 & 11454 & 11454 & 11454 & 11454 & 11454 \\
\hline$R^{2}$ & 0.01 & 0.01 & 0.01 & 0.02 & 0.01 & 0.04 \\
\hline Control Group Mean & 0.03 & 0.05 & 0.12 & 0.09 & 0.04 & 0.54 \\
\hline
\end{tabular}

Notes: Outcomes from the first follow-up survey. These are responses to: "What is the most important factor you think about when selecting schools." The options were: Distance from home; Cost; Chances of being admitted; Academic performance of the school; (any of) Teacher quality, Reputation of the school, Facilities and resources; Boys or girls only; Religious affiliation; Family member attended; How it might affect my future success; Discipline or behavior of past students. Each column represents one regression, which controls for gender and includes strata fixed effects. Linear probability models. Standard errors adjusted for clustering at the JHS level appear in parenthesis, ${ }^{*} \mathrm{p}<0.1,{ }^{* *} \mathrm{p}<0.05,{ }^{* * *} \mathrm{p}<0.01$. 


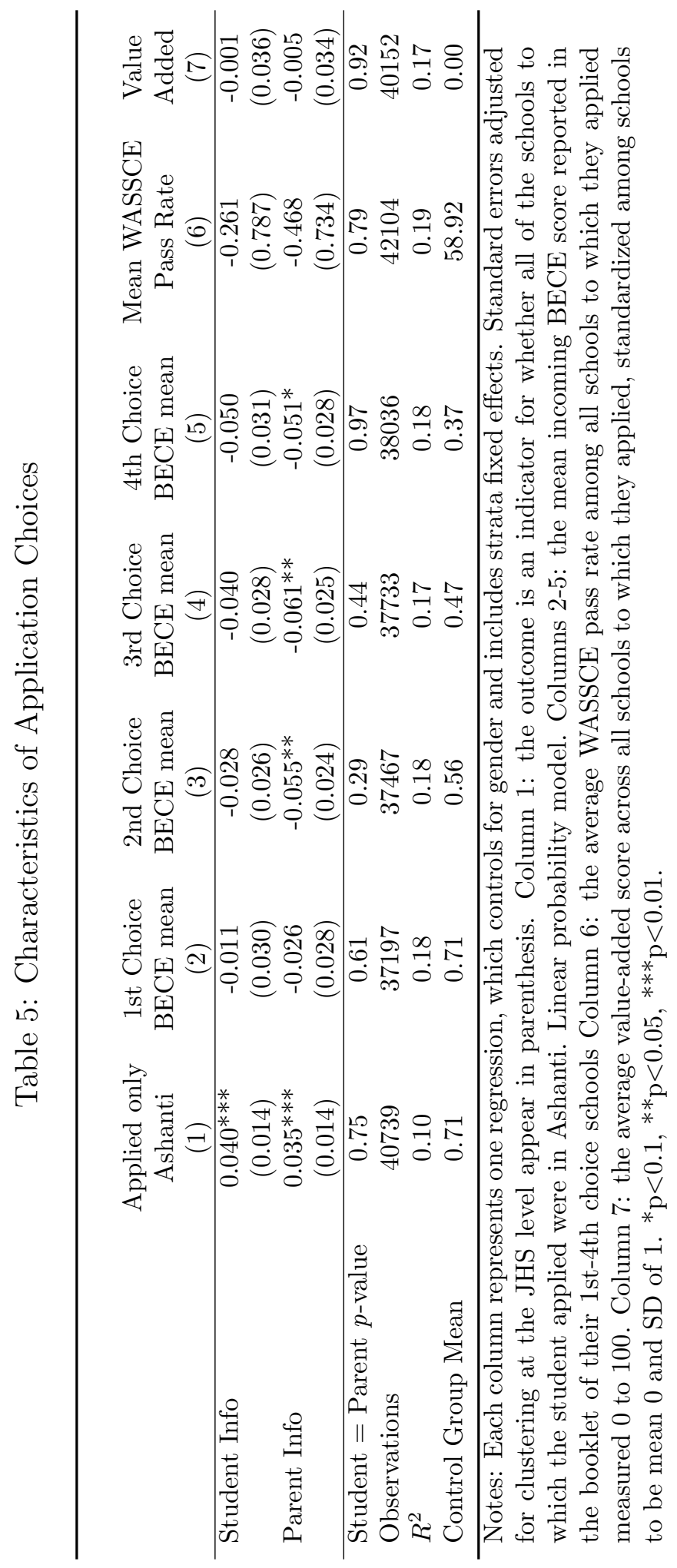


Table 6: Junior High School Exit Exam

\begin{tabular}{lcc}
\hline & Took & BECE \\
& BECE & Score \\
& $(1)$ & $(2)$ \\
\hline Student Info & -0.004 & -0.012 \\
& $(0.008)$ & $(0.080)$ \\
Parent Info & -0.007 & -0.045 \\
& $(0.008)$ & $(0.074)$ \\
\hline Student = Parent $p$-value & 0.78 & 0.66 \\
Observations & 42228 & 41159 \\
$R^{2}$ & 0.04 & 0.12 \\
Control Group Mean & 0.98 & 0.00 \\
\hline
\end{tabular}

Notes: Each column represents one regression, which controls for gender and includes strata fixed effects. Standard errors adjusted for clustering at the JHS level appear in parenthesis. Outcomes from CSSPS administrative data. ${ }^{*} \mathrm{p}<0.1,{ }^{* *} \mathrm{p}<0.05,{ }^{* * *} \mathrm{p}<0.01$.

Table 7: Admissions

\begin{tabular}{lccc}
\hline & Admitted & Admitted & Admitted \\
& Any School & Any Choice & 1st Choice \\
& $(1)$ & $(2)$ & $(3)$ \\
\hline Student Info & 0.011 & 0.007 & -0.001 \\
& $(0.018)$ & $(0.020)$ & $(0.014)$ \\
Parent Info & 0.019 & 0.027 & 0.001 \\
& $(0.015)$ & $(0.021)$ & $(0.014)$ \\
\hline Student = Parent $p$-value & 0.61 & 0.32 & 0.92 \\
Observations & 42228 & 42228 & 42228 \\
$R^{2}$ & 0.32 & 0.18 & 0.12 \\
Control Group Mean & 0.84 & 0.53 & 0.20 \\
\hline
\end{tabular}

Notes: Each column represents one regression, which controls for gender and includes strata fixed effects. Standard errors adjusted for clustering at the JHS level appear in parenthesis. Outcomes from the CSSPS administrative data. Each outcome is an indicator variable. Linear probability models. ${ }^{*} \mathrm{p}<0.1,{ }^{* *} \mathrm{p}<0.05$, $* * * \mathrm{p}<0.01$. 
Table 8: Admissions Characteristics

\begin{tabular}{|c|c|c|c|}
\hline & $\begin{array}{l}\text { Admitted } \\
\text { Ashanti } \\
\text { (1) }\end{array}$ & $\begin{array}{l}\text { Admitted SHS } \\
\text { BECE mean } \\
(2)\end{array}$ & $\begin{array}{c}\text { Admitted SHS } \\
\text { Value Added } \\
(3)\end{array}$ \\
\hline Student Info & $\begin{array}{c}0.028 \\
(0.019)\end{array}$ & $\begin{array}{c}-0.054^{*} \\
(0.032)\end{array}$ & $\begin{array}{c}0.037 \\
(0.025)\end{array}$ \\
\hline Parent Info & $\begin{array}{c}0.043^{* * *} \\
(0.015)\end{array}$ & $\begin{array}{c}-0.070^{* *} \\
(0.033)\end{array}$ & $\begin{array}{c}0.080^{* * *} * \\
(0.024)\end{array}$ \\
\hline Student $=$ Parent $p$-value & 0.35 & 0.60 & 0.07 \\
\hline Observations & 42228 & 28147 & 27896 \\
\hline$R^{2}$ & 0.22 & 0.05 & 0.08 \\
\hline Control Group Mean & 0.75 & 0.02 & -0.00 \\
\hline
\end{tabular}

Notes: Each column represents one regression, which controls for gender and includes strata fixed effects. Standard errors adjusted for clustering at the JHS level appear in parenthesis. Column 1 is whether the student was assigned to a school in Ashanti, conditional on having been assigned anywhere. Column 2 is the average of all of the booklet-reported BECE scores in the booklet. Column 3 is the residual from a regression of the school's booklet-reported SSCE pass-rate on the booklet-reported incoming BECE means and 5th percentiles in each program. Missing incoming scores (for example, if a school does not offer a program) are included with the mean for that program across schools and an indicator for missing that variable. ${ }^{*} \mathrm{p}<0.1,{ }^{* *} \mathrm{p}<0.05$, $* * * \mathrm{p}<0.01$.

Table 9: Matriculation

\begin{tabular}{lcccc}
\hline & $\begin{array}{c}\text { Currently } \\
\text { Attending SHS } \\
(1)\end{array}$ & $\begin{array}{c}\text { Started on Time } \\
\text { if Attending }\end{array}$ & $\begin{array}{c}\text { Attending } \\
\text { Admitted SHS }\end{array}$ & $\begin{array}{c}\text { Attending SHS } \\
\text { in Ashanti } \\
(4)\end{array}$ \\
\hline Student Info & -0.008 & -0.018 & -0.003 & -0.008 \\
& $(0.023)$ & $(0.024)$ & $(0.018)$ & $(0.024)$ \\
Parent Info & -0.024 & -0.040 & 0.033 & -0.015 \\
& $(0.022)$ & $(0.025)$ & $(0.020)$ & $(0.023)$ \\
\hline Student = Parent $p$-value & 0.52 & 0.40 & 0.09 & 0.76 \\
Observations & 7654 & 3751 & 7087 & 7654 \\
$R^{2}$ & 0.06 & 0.07 & 0.03 & 0.07 \\
Control Group Mean & 0.60 & 0.44 & 0.23 & 0.51 \\
\hline
\end{tabular}

Notes: Each column represents one regression, which controls for gender and includes strata fixed effects. Standard errors adjusted for clustering at the JHS level appear in parenthesis. Outcomes from the secondary school follow-up survey. Linear probability models. Column 1: the outcome is an indicator if the student was attending secondary school at the time of the follow-up. Column 2: the outcome is an indicator for whether the student reported having started secondary school in the first 6 weeks, conditional on attending at all. Column 3: outcome is an indicator for whether the student reported that they were attending the school to which they were assigned. Column 4: outcome is an indicator for whether they are currently attending secondary school in Ashanti. ${ }^{*} \mathrm{p}<0.1,{ }^{* *} \mathrm{p}<0.05,{ }^{* * *} \mathrm{p}<0.01$. 


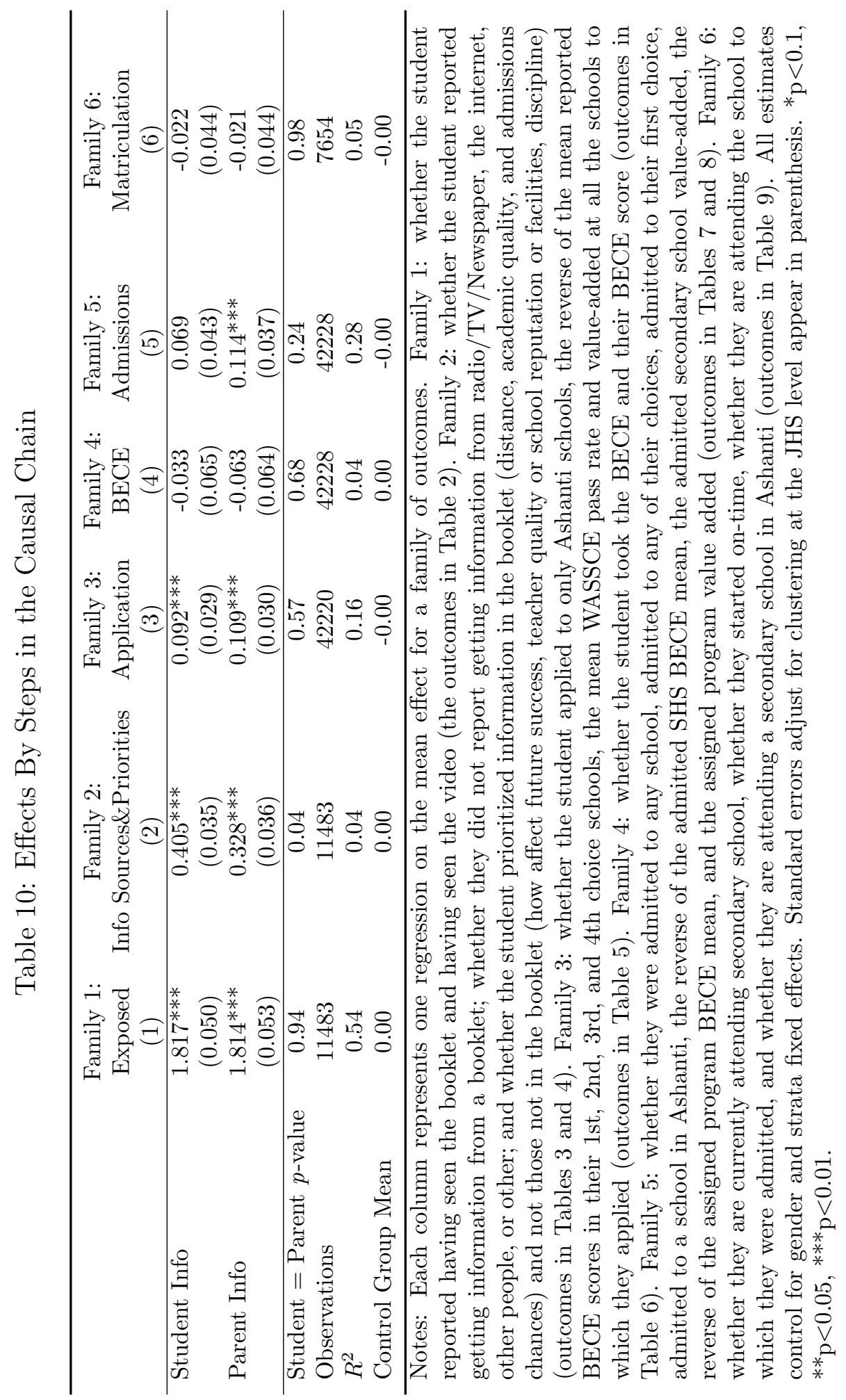




\section{Appendix}

In the tables that follow we provide additional outcomes and tests of heterogeneity. 


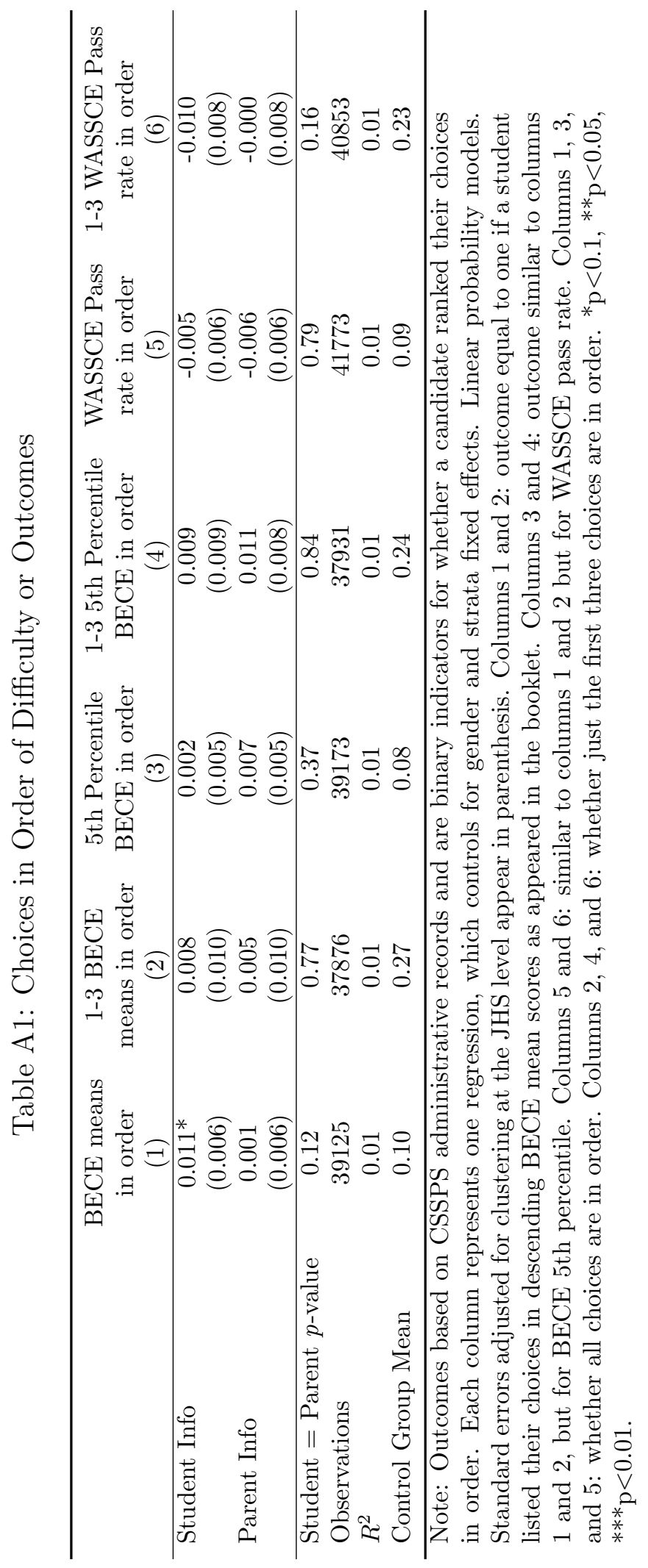


Table A2: Salience of Potential Choices

\begin{tabular}{|c|c|c|c|c|}
\hline & \multicolumn{2}{|c|}{ Number of Choices From: } & \multicolumn{2}{|c|}{$\begin{array}{l}\text { Fraction of Classmates } \\
\text { Who Applied to Same: }\end{array}$} \\
\hline & $\begin{array}{c}\text { Top of } \\
\text { Booklet Page } \\
\text { (1) }\end{array}$ & $\begin{array}{c}\text { 1st page of } \\
\text { Booklet } \\
(2)\end{array}$ & $\begin{array}{c}1 \text { st } \\
\text { choice } \\
(3)\end{array}$ & $\begin{array}{l}\text { 4th } \\
\text { choice } \\
\text { (4) }\end{array}$ \\
\hline Student Info & $\begin{array}{l}-0.011 \\
(0.022)\end{array}$ & $\begin{array}{c}0.023 \\
(0.019)\end{array}$ & $\begin{array}{l}-0.002 \\
(0.011)\end{array}$ & $\begin{array}{l}-0.013 \\
(0.010)\end{array}$ \\
\hline Parent Info & $\begin{array}{l}-0.011 \\
(0.020)\end{array}$ & $\begin{array}{c}0.056^{* * *} \\
(0.020)\end{array}$ & $\begin{array}{l}-0.001 \\
(0.010)\end{array}$ & $\begin{array}{c}-0.018^{*} \\
(0.010)\end{array}$ \\
\hline Student $=$ Parent $p$-value & 0.98 & 0.10 & 0.94 & 0.57 \\
\hline Observations & 42228 & 42228 & 42228 & 42228 \\
\hline$R^{2}$ & 0.11 & 0.06 & 0.20 & 0.13 \\
\hline Control Group Mean & 0.46 & 0.55 & 0.25 & 0.28 \\
\hline
\end{tabular}

Notes: Outcomes based on CSSPS administrative records. Each column represents one regression, which controls for gender and strata fixed effects. Standard errors adjusted for clustering at the JHS level appear in parenthesis. Column 1: the number of choices listed that appeared on the top of a page in the booklet. Column 2: the number of choices listed that appeared on the first page of the booklet (first 14 Option 1 schools by alphabetical order). Column 3: the fraction of classmates, including the reference student, who applied to the candidate's first choice school. Column 4: the fraction of classmates, including the reference student, who applied to the candidate's 4 th choice school. ${ }^{*} \mathrm{p}<0.1,{ }^{*} \mathrm{p}<0.05$, $* * * \mathrm{p}<0.01$.

Table A3: Heterogenous Effects by Completing the Baseline Survey

\begin{tabular}{lccc}
\hline & $\begin{array}{c}\text { Family 3: } \\
\text { Application } \\
(1)\end{array}$ & $\begin{array}{c}\text { Family 4: } \\
\text { BECE } \\
(2)\end{array}$ & $\begin{array}{c}\text { Family 5: } \\
\text { Admissions } \\
\end{array}$ \\
\hline Student Info & $0.092^{* * *}$ & -0.098 & 0.069 \\
& $(0.034)$ & $(0.081)$ & $(0.057)$ \\
Parent Info & $0.111^{* * *}$ & $-0.107^{*}$ & $0.127^{* * *}$ \\
& $(0.035)$ & $(0.065)$ & $(0.046)$ \\
Student & 0.000 & 0.195 & 0.002 \\
info*Surveyed & $(0.054)$ & $(0.119)$ & $(0.072)$ \\
Parent info*Surveyed & -0.008 & 0.132 & -0.038 \\
& $(0.054)$ & $(0.112)$ & $(0.065)$ \\
Surveyed & 0.026 & -0.089 & 0.054 \\
& $(0.040)$ & $(0.077)$ & $(0.048)$ \\
\hline Student = Parent $p$-value & 0.567 & 0.917 & 0.242 \\
Observations & 42220 & 42228 & 42228 \\
$R^{2}$ & 0.155 & 0.037 & 0.276 \\
Control Group Mean & 0.084 & -0.082 & 0.051 \\
\hline
\end{tabular}

Notes: Each column represents one regression on the mean effect for a Family of outcomes. See Table 10 for additional details on Family construction. Survey status assigned at the school level. Each column represents one regression, which controls for gender and strata fixed effects. Standard errors adjusted for clustering at the JHS level appear in parenthesis. ${ }^{*} \mathrm{p}<0.1,{ }^{* *} \mathrm{p}<0.05,{ }^{* * *} \mathrm{p}<0.01$. 


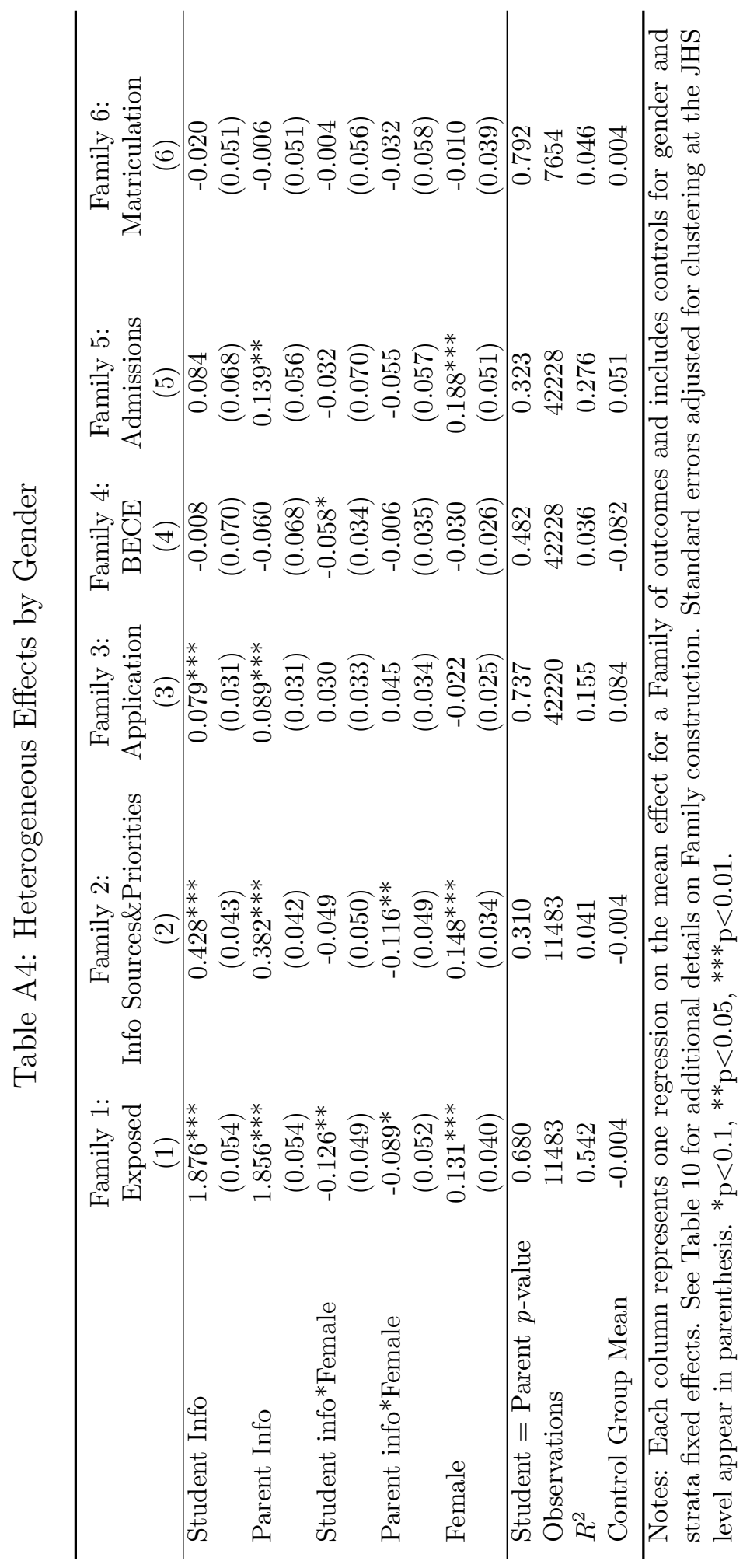




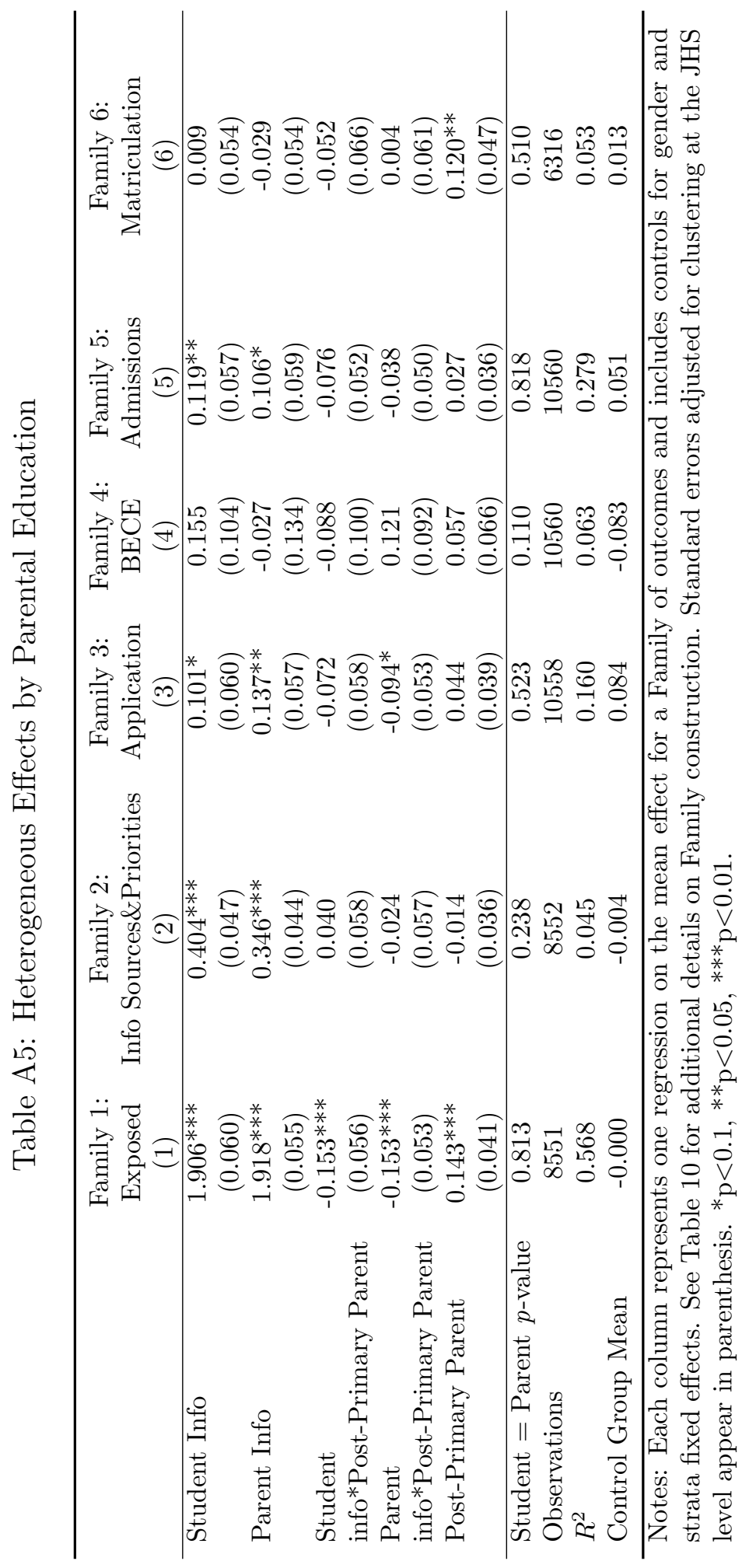




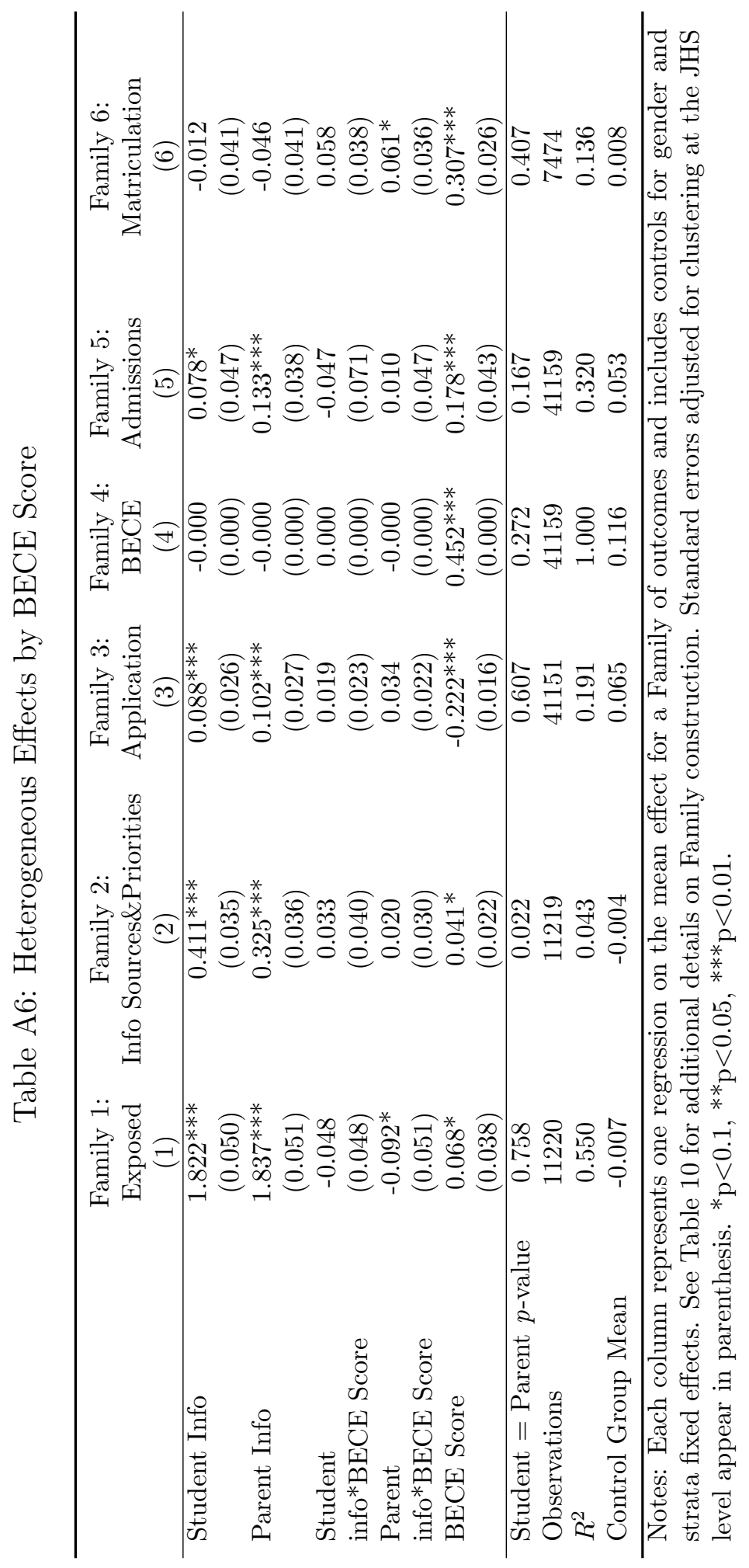




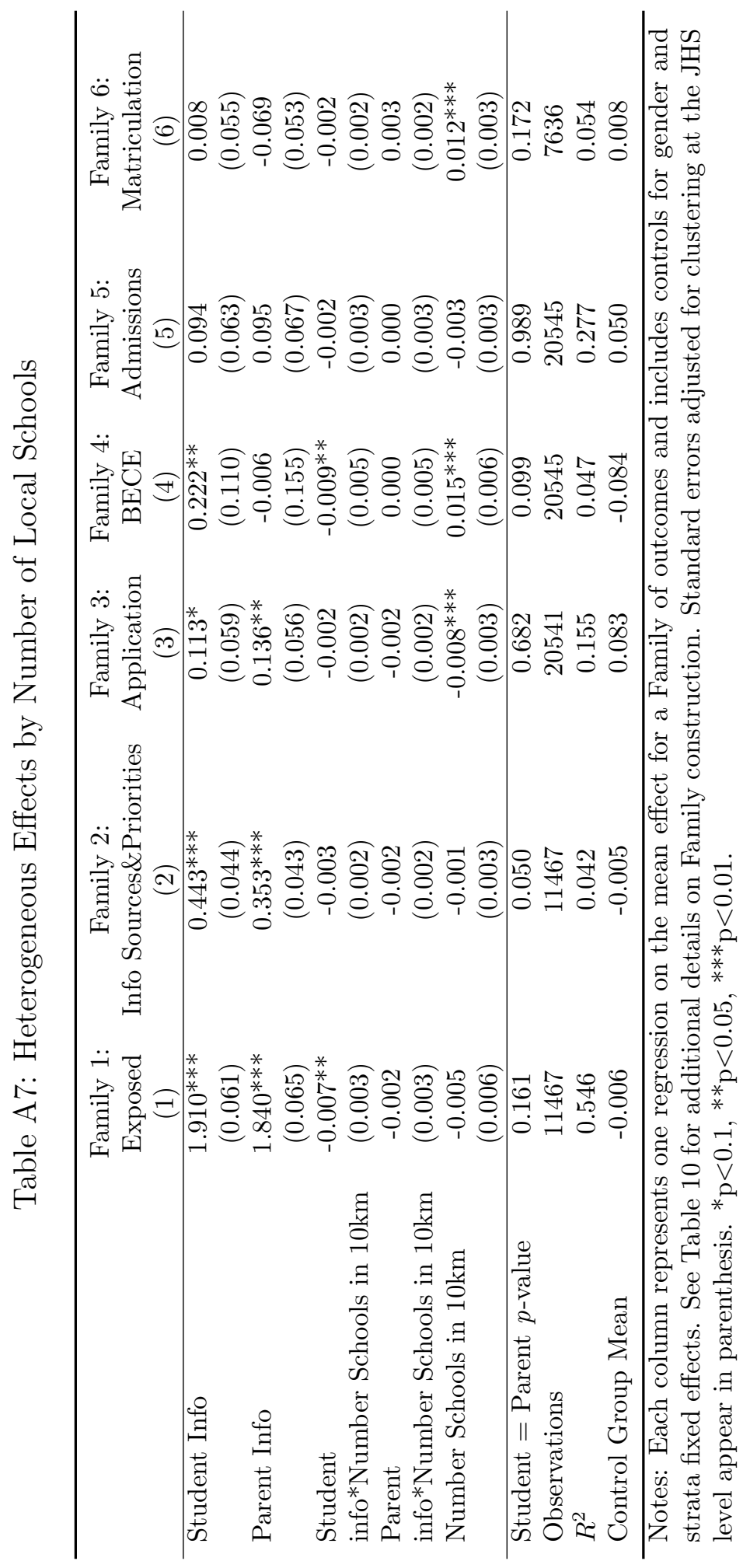

